\title{
The mesolimbic dopamine signatures of relapse to alcohol-seeking
}

\author{
Yu Liu ${ }^{1}$, Philip Jean-Richard-dit-Bressel ${ }^{1}$, Joanna Oi-Yue Yau ${ }^{1}$, Alexandra Willing ${ }^{1}$, Asheeta A. Prasad, John M. Power ${ }^{2}$, \\ Simon Killcross ${ }^{1}$, Colin W.G. Clifford ${ }^{1}$, Gavan P. McNally ${ }^{1^{*}}$ \\ ${ }^{1}$ School of Psychology, UNSW Sydney, Australia. \\ ${ }^{2}$ Department of Physiology and Translational Neuroscience Facility, School of Medical Sciences, UNSW Sydney, Australia.
}

Correspondence: Gavan P. McNally, g.mcnally@unsw.edu.au

\begin{abstract}
The mesolimbic dopamine system comprises distinct compartments supporting different functions in learning and motivation. Less well understood is how complex addiction-related behaviors emerge from activity patterns across these compartments. Here we show how different forms of relapse to alcohol-seeking are assembled from activity across the ventral tegmental area and the nucleus accumbens. Using gCaMP and dLight fibre photometry, we show that self-administration and two forms of relapse (renewal/context-induced reinstatement and reacquisition) are associated with recruitment across the mesolimbic dopamine system. Using a variety of interventions, we show that this activity is causal to both forms of relapse. Finally, we use dissimilarity matrices to identify mesolimbic dopamine signatures of self-administration, extinction, and relapse. We show that signatures of relapse can be identified from heterogeneous activity profiles across the mesolimbic dopamine system and that these signatures differ for different forms of relapse.
\end{abstract}

\section{Introduction}

It is axiomatic that the actions of dopamine are critical to drug addiction. Dopamine mediates the reinforcing effects of drugs of abuse, instructs learning about behavioral as well as environmental antecedents to these effects, and contributes to action selection controlling drug seeking and drug taking (Everitt et al., 2008; Luscher, 2015; Nutt et al., 2015). Moreover, exposure to drugs of addiction can profoundly alter these functions (Volkow et al., 2017).

Much remains to be learned about these roles of dopamine in addiction. Chief among these is how dopamine contributes to relapse. A persistent propensity to relapse is a diagnostic feature of drug addiction and remains a primary impediment to successful long-term treatment (Association, 2013; Jonas et al., 2014). In animal models, dopamine mediates various forms of relapse to drug seeking (cue-, stress-, priming, context/renewal reinstatement) because these can be prevented by systemic or local manipulation of ventral tegmental area (VTA) and nucleus accumbens (Acb) (Bossert et al., 2013; Bossert et al., 2007; Chaudhri et al., 2009; Gibson et al., 2018; Hamlin et al., 2007; Mahler et al., 2014; McFarland and Kalivas, 2001; Schmidt et al., 2005). However, the mesolimbic dopamine system has a complex architecture. VTA dopamine neurons form distinct channels linked to differences in behavioral and motivational function (Cohen et al., 2012; de Jong et al., 2019; Heymann et al., 2019; Lammel et al., 2008; Lammel et al., 2011; Lammel et al., 2013; Saunders et al., 2018; Tian et al., 2016; Watabe-Uchida et al., 2012). In turn, there are distinct profiles of dopamine release across compartments of the ventral striatum giving rise to different functions (de Jong et al., 2019; Mohebi et al., 2019).

Relapse is presumably assembled from activity across the mesolimbic dopamine system. But how relapse relates to activity in specific VTA and accumbens compartments, whether this is the same for different forms of relapse, and how relapse-associated activity relates to activity during selfadministration or extinction/abstinence are unknown. Here we answered these questions by studying the temporal dynamics of activity across spatially distinct compartments of the mesolimbic dopamine system. We show that signatures of relapse can be identified from heterogeneous activity profiles across the mesolimbic dopamine system and that these signatures differ for different forms of relapse.

\section{Materials and Methods}

\section{Subjects}

Subjects were adult male Long-Evans (School of Psychology, UNSW Australia) or Th-Cre (SD- Th-cre ${ }^{\text {tmlsage }}$ ) (Sage Laboratories, Cambridge, United Kingdom) rats. They were housed in ventilated racks, in groups of 4 , on corn cob bedding in a climate-controlled colony room maintained on 12:12 hour light/dark cycle (0700 lights on). Rats had free access to food (Gordon's Rat Chow) and water until two days prior to commencement of behavioral training when they received 1 hour of access to food and water each day for the remainder of the experiment. All subjects were randomly allocated to experimental conditions. All studies were performed in accordance with the Animal Research Act 1985 (NSW), under the guidelines of the National Health and Medical Research Council Code for the Care and Use of Animals for Scientific Purposes in Australia (2013). The UNSW Animal Care and Ethics Committee approved all procedures.

\section{Surgery}

Rats were anaesthetized via i.p. injection with a mixture of $1.3 \mathrm{ml} / \mathrm{kg}$ ketamine anaesthetic (Ketamil; Troy Laboratories, NSW, Australia) at a concentration of $100 \mathrm{mg} / \mathrm{ml}$ and $0.3 \mathrm{ml} / \mathrm{kg}$ of the muscle relaxant xylazine (Xylazil; Troy Laboartories, NSW, Australia) at a concentration of 20 $\mathrm{mg} / \mathrm{ml}$. Rats received a subcutaneous injection of $0.1 \mathrm{ml} 50 \mathrm{mg} / \mathrm{ml}$ carprofen (Pfizer, Inc., Tadworth, United Kingdom) before being placed in the stereotaxic frame (Kopf Instruments, CA, USA). Rats received stereotaxic surgery using the following flat skull coordinates relative to bregma (in $\mathrm{mm}$ ):

\begin{tabular}{|l|l|l|l|}
\hline Location A-P & A-L & D-V \\
\hline $\begin{array}{l}\text { VTA A } \\
\text { (bilateral) }\end{array}$ & -5.8 & \pm 2.25 & $\begin{array}{l}-8.3\left(10^{\circ}\right. \\
\text { angle) }\end{array}$ \\
\hline $\begin{array}{l}\text { mVTA AAV } \\
\text { (unilateral) }\end{array}$ & -5.8 & -0.5 & -8.15 \\
\hline $\begin{array}{l}\text { lVTA AAV } \\
\text { (unilateral) }\end{array}$ & -5.8 & -1 & -8.15 \\
\hline $\begin{array}{l}\text { VTA Optic Fibers } \\
\text { (bilateral) }\end{array}$ & -5.8 & \pm 2.25 & $\begin{array}{l}-7.8\left(10^{\circ}\right. \\
\text { angle) }\end{array}$ \\
\hline $\begin{array}{l}\text { mVTA Optic Fibers } \\
\text { (unilateral) }\end{array}$ & -5.8 & -0.5 & -7.65 \\
\hline $\begin{array}{l}\text { lVTA Optic Fibers } \\
\text { (unilateral) }\end{array}$ & -5.8 & -1 & -7.65 \\
\hline
\end{tabular}




\begin{tabular}{|lr|l|l|l|}
\hline $\begin{array}{l}\text { AcbShM \& } \\
\text { NAcCore AAV } \\
\text { (unilateral) }\end{array}$ & +1.2 & -0.8 & -7.5 \\
\hline $\begin{array}{l}\text { AcbShL AAV } \\
\text { (unilateral) }\end{array} \quad+1.2$ & -2.8 & -7.5 \\
\hline $\begin{array}{l}\text { AcbShM \& } \\
\text { NAcCore Optic } \\
\text { Fibers (unilateral) }\end{array}$ & +1.2 & -0.8 & -7 \\
\hline $\begin{array}{l}\text { AcbShL Optic } \\
\text { Fibers (unilateral) }\end{array}$ & +1.2 & -2.8 & -7 \\
\hline
\end{tabular}

Vectors $(0.5 \mu \mathrm{l} \mathrm{hM} 4 \mathrm{Di}$ and KORD, $0.75 \mu \mathrm{l}$ otherwise) were infused with a 23-gauge, cone tipped $5 \mu \mathrm{l}$ stainless steel injector (SGE Analytical Science, Australia) over 3 min using an infusion pump (UMP3 with SYS4 Micro-controller, World Precision Instruments, Inc., FL, USA). The needle was left in place for $7 \mathrm{~min}$ to allow for diffusion of and reduce spread up the infusion tract. Optic cannulae for relevant experiments were implanted during a concurrent stereotaxic procedure and secured using jeweller's screws and dental cement (Vertex Dental, The Netherlands). At the end of surgery, rats received i.p. injection of $0.2 \mathrm{ml}$ of $150 \mathrm{mg} / \mathrm{ml}$ solution of procaine penicillin (Benacillin; Troy Laboratories, NSW, Australia) and $0.2 \mathrm{ml}$ of $100 \mathrm{mg} / \mathrm{ml}$ cephazolin sodium (AFT Pharmaceuticals, NSW, Australia). iP rats received the antibiotic baytril (3mg/kg, i.p) and the anti-inflammatory drug meloxicam (3mg/kg, i.p). All rats were monitored daily for weight and/or behavioral changes.

\section{Behavioural Procedures \\ Apparatus}

Standard rat operant chambers (ENV-008) (Med Associates, VT, USA) with dimensions $29.5 \mathrm{~cm}$ (width) x $24.8 \mathrm{~cm}$ (length) x $18.7 \mathrm{~cm}$ (height) were used for all alcohol self-administration and extinction procedures. The chambers contained two nosepoke holes symmetrically located on one sidewall of the chamber, $3 \mathrm{~cm}$ above a grid floor. A recessed magazine was located behind a $4 \times 4 \mathrm{~cm}$ opening in the center of the same wall between the two nosepokes. Responding on one (active) nosepoke extinguished the cue light in the nosepoke and triggered a syringe pump to deliver alcoholic beer to the magazine during acquisition training, whereas responding on the other (inactive) nosepoke had no programmed consequences. A computer running MedPC-IV software controlled all events. For optogenetic experiments, an LED plus fiber-optic rotary joint and LED driver (Doric Lenses Inc., Quebec, Canada) was suspended above each chamber and controlled by MedPC-IV. For fibre photometry, the patch cable was supported by a gimbal and counterweighted arm. The eight self-administration chambers were divided into two groups of four to serve as distinct contexts for experiments with context as a factor. These chambers differed in their olfactory (rose vs peppermint essence), tactile (grid vs Perspex flooring) and visual (light on vs off) properties. These two contexts were counterbalanced to serve as the training (context A) and extinction (context B) contexts. All fiber optic cannulae and patch cables were hand fabricated and tested using parts from Thor Labs (Newton, NJ, USA). Construction procedure was adapted from the protocol described by Sparta et al. (2012). Fiber optic cannulae and patch cables were fabricated from $0.39 \mathrm{NA}, \varnothing 400 \mu \mathrm{m}$ core multimode optical fiber and ceramic ferrules (Thor Labs, Newton, NJ, USA).

Locomotor chambers (ENV-515) (Med Associates, VT, USA) with dimensions $43.4 \mathrm{~cm}$ (width) x $43.4 \mathrm{~cm}$ (length) x $30.3 \mathrm{~cm}$ (height) were used for locomotor assessment. Movement was tracked with three 16 beam infrared arrays. Infrared beams were located on both the $\mathrm{x}$ - and $\mathrm{y}-$ axes for positional tracking.

\section{General behavioral testing procedures}

All behavioral procedures commenced a minimum of 4 weeks after surgery. On the first two days, the rats received 20 min magazine training sessions in context A and context B, counterbalanced order. During these sessions, there were 10 non-contingent deliveries of $0.6 \mathrm{ml}$ of the reward (4\% alcohol (v/v) decarbonated beer; Coopers Brewing Company, Australia) at time intervals variable around a mean of $1.2 \mathrm{~min}$. On the next ten days rats received self-administration training in context A for 1 hour per day (unless otherwise stated). Responding on the active nosepoke extinguished the nosepoke cue light and triggered delivery via syringe pump of $0.6 \mathrm{ml}$ alcoholic beer to the magazine on an FR-1 schedule followed by a 24 seconds timeout. Responses on the inactive nosepoke were recorded but had no consequences. On the next four days, rats received extinction training in context $\mathrm{B}$ for $1 \mathrm{~h}$ per day (unless otherwise stated). During this training, responses on the active nosepoke extinguished the cue light and triggered the pump but no beer was delivered.

Testing commenced 24 hours after extinction. Rats were tested for 1 hour in the extinction context $(\mathrm{ABB})$ and for 1 hour in the training context (ABA) for expression of extinction and renewal (context-induced reinstatement), respectively. The order of tests was counterbalanced and tests were 24 hours apart. Tests were identical to self-administration except that the syringe pump was empty. Rats were tested 24 hours later for 1 hour reacquisition of alcoholic beer seeking in the training context. Our past research has shown no impact of the prior order of ABA and $\mathrm{ABB}$ testing on responding during reacquisition. Unless otherwise stated, tests lasted $60 \mathrm{~min}$. We selected these procedures based on our past work that has shown robust context-induced reinstatement and reacquisition under these conditions(Hamlin et al., 2007; Gibson et al., 2018).

Chemogenetic hM4Di inhibition of $V T A^{T h}$ neurons on renewal, reacquisition and locomotor activity

There were two groups of Th Cre+/- rats. Group eYFP $(n=6)$ whereas group hM4Di $(n=8)$ received AAV5-hSyn-DIO-hM4D(Gi)-mCherry bilaterally in the VTA. Rats were trained, extinguished, and tested as described above. Rats received an i.p. injection $0.1 \mathrm{mg} / \mathrm{kg}$ of clozapine (\#C6305, Sigma Aldrich; $1 \mathrm{ml} / \mathrm{kg}$ diluted, 5\% DMSO and saline) $15 \mathrm{~min}$ prior to tests. They then received two days of 30 minutes habituation each day in locomotor chambers, rats were tested for locomotor activity (30 min) 15 min after i.p. injection of saline or clozapine. The order of tests (saline or clozapine) were counterbalanced and 24 hours apart.

Chemogenetic KORD inhibition of $V T A^{T h}$ neurons on reacquisition. There were two groups of Th Cre+/- rats. Group eYFP $(n=6)$ received AAV5-hSyn-DIO-eYFP whereas group hM4Di $(n=8)$ received AAV8hSyn-DIO-KORD-mCitrine, bilaterally in the VTA. Rats were trained, extinguished, and tested as described above with the exceptions that all training and testing occurred in a single context and rats were tested for reacquisition only, 24 hours after last extinction session. Rats were injected s.c. with salvinorin B (SalB) (Apple Pharms Ingredients Inc, NC, USA; (15 mg/kg, $0.5 \mathrm{ml} / \mathrm{kg}$ ) $15 \mathrm{~min}$ prior to reacquisition. salvinorin B was dissolved in 100\% dimethyl-sulfoxide (DMSO). Rats had been habituated to the s.c. injection procedure via 4 daily injections $(0.5 \mathrm{ml} / \mathrm{kg}$, $100 \%$ DMSO).

Fiber photometry of Ca2+ transients in $V T A^{T h}$ neurons during acquisition, extinction, renewal and reacquisition

There was one group of Th $\mathrm{Cre}+/-$ rats $(n=24)$ with fibers targeted unilaterally at the IVTA $(n=16)$ or mVTA $(n=8)$. Rats received AAV5hSyn.Flex.GCaMP6f.WPRE.SV40 eYFP unilaterally in the VTA. Rats were trained, extinguished, and tested as described above. Fiber 
photometry recordings were made on Days 2 and 10 of selfadministration training and Day 1 of extinction training. These sessions were $60 \mathrm{~min}$ duration and recordings were made for the first $30 \mathrm{~min}$. Recordings were also made during tests for extinction (ABB), renewal (ABA), and reacquisition. These sessions were $30 \mathrm{~min}$ in duration and recordings were made for $30 \mathrm{~min}$.

\section{Optogenetic inhibition of $V T A$ on renewal and reacquisition}

There was one group of Th Cre-/- rats $(n=8)$ and two groups of $\mathrm{Cre}+/-$ rats with fibers targeted bilaterally at IVTA $(n=6)$ or mVTA $(n=6)$. Rats were trained and tested as described above, except the test sessions were $30 \mathrm{~min}$ in duration. During tests, rats were connected to patch cables attached to 625nm LEDs (Doric Lenses Inc., Quebec, Canada) and received optical stimulation for 10 seconds after each nosepoke during the FR (Nosepoke+) but not during the timeout (Nosepoke-). Rats had been habituated to patch cables on Days 6 and 7 of acquisition and Days 2 and 3 of extinction.

\section{D1 dopamine receptor antagonist on renewal, reacquisition and locomotor activity}

There 4 groups of rats injected with either $0(n=8), 0.025(n=8), 0.1(n$ $=8)$, or $0.25(n=8) \mathrm{mg} / \mathrm{kg} \mathrm{SCH} 39166$. Rats were trained, extinguished, and tested as described above. Rats received s.c. injections of SCH31966 or saline $15 \mathrm{~min}$ prior to test sessions. Then then received two days of 30 minutes habituation to the locomotor chambers prior to being tested for locomotor activity (30min). Rats all received s.c. injection of saline and SCH39166 at the same dose they had received during relapse tests. a dose corresponding to their group. The order of these tests (saline and SCH39166) was counterbalanced and tests were 24 hours apart.

\section{Fiber photometry of dopamine transients in Acb during acquisition, extinction, renewal and reacquisition}

There were three groups of rats with AAV and fibers targeted unilaterally at the $\operatorname{AcbShM}(n=6), \operatorname{AcbC}(n=7)$, or AcbShL $(n=5)$. Rats received AAV5-CAG-dLight1.1 and optic fibers unilaterally in the Acb. Fiber photometry recordings were made on Days 2 and 10 of selfadministration and Day 1 of extinction training. These sessions were 60 min duration and recordings were made for the first $30 \mathrm{~min}$. Recordings were also made during tests for extinction $(\mathrm{ABB})$, renewal (ABA), and reacquisition. These sessions were $30 \mathrm{~min}$ in duration and recordings were made for $30 \mathrm{~min}$.

\section{Fibre photometry}

Recordings were performed using Fibre Photometry Systems from Doric Lenses and Tucker Davis Technologies (RZ5P, Synapse). Two excitation wavelengths, $465 \mathrm{~nm}\left(\mathrm{Ca}^{2+}\right.$ - dependent signal) and $405 \mathrm{~nm}$ (isosbestic control signal) emitted from LEDs (465nm: LEDC1-B_FC, 405nm: LEDC1-405_FC; Doric Lenses), controlled via dual channel programmable LED drivers (LEDD_4, Doric Lenses), were channeled into $0.39 \mathrm{NA}, \varnothing 400 \mu \mathrm{m}$ core multimode pre-bleached patch cables via a Doric Dual Fluorescence Mini Cube (FMC2, Doric Lenses). Light intensity at the tip of the patch was maintained at $10-30 \mu \mathrm{W}$ across sessions. GCaMP6, dLight1.1 and isosbestic fluorescence, wavelengths were measured using femtowatt photoreceivers (Newport, 2151). Synapse software controlled and modulated excitation lights $(465 \mathrm{~nm}$ : $209 \mathrm{~Hz}, 405 \mathrm{~nm}: 331 \mathrm{~Hz}$ ), as well as demodulated and low-pass filtered $(3 \mathrm{~Hz})$ transduced fluorescence signals in real-time via the RZ5P. Synapse/RZ5P also received Med-PC signals to record behavioral events and experimenter-controlled stimuli in real time.

\section{Histology and Immunohistochemistry}

eYFP/mCherry immunohistochemistry

Rats were deeply anesthetized with sodium pentobarbital $(100 \mathrm{mg} / \mathrm{kg}$, i.p.; Virbac, NSW, Australia) and perfused transcardially with $200 \mathrm{ml}$ of $0.9 \%$ saline, containing heparin $(360 \mu \mathrm{l} / \mathrm{L})$ and sodium nitrite $(12.5 \mathrm{ml} / \mathrm{L})$, followed by $400 \mathrm{ml}$ of $4 \%$ paraformaldehyde in $0.1 \mathrm{M}$ phosphate buffer (PB), $\mathrm{pH} 7.4$. Brains were extracted from the skull and post fixed for one hour in the same fixative and then placed in $20 \%$ sucrose solution overnight. Brains were frozen and sectioned coronally at $40 \mu \mathrm{m}$ using a cryostat (Leica CM1950).

To visualize eYFP, mCherry. mCitrine immunoreactivity (-IR) (Rabbit anti-eGFP Polyclonal Antibody, Cat\#AA11122; RRID AB_221569; Rabbit anti-mCherry Polyclonal Antibody, Cat\#PA5-34974; RRID AB_2552323 ThermoFisher Scientific) four serially adjacent sets of sections from the regions of interest were obtained from each brain and stored in $0.1 \%$ sodium azide in $0.1 \mathrm{M} \mathrm{PBS}, \mathrm{pH} 7.2$. Sections were washed in $0.1 \mathrm{M} \mathrm{PB}$, followed by $50 \%$ ethanol, $50 \%$ ethanol with $3 \%$ hydrogen peroxidase, then 5\% normal horse serum (NHS) in PB (30 minutes each). Sections were then incubated in rabbit antiserum against eGFP or mCherry (1:2000; ThermoFisher Scientific, MA, USA) in a PB solution containing $2 \%$ NHS and $0.2 \%$ Triton X-10 (48 hours at $4^{\circ} \mathrm{C}$ ). The sections were then washed and incubated in biotinylated donkey antirabbit (1:1000; 24 hours at 4C; Biotin Donkey Anti-Rabbit Cat\#711-065152; RRID:AB_2540016 Jackson ImmunoResearch Laboratories, PA, USA). Finally, sections were incubated in avidin-biotinylated horseradish peroxidase complex $(6 \mu \mathrm{l} / \mathrm{ml}$ avidin and $6 \mu \mathrm{l} / \mathrm{ml}$ biotin; 2 hours at room temperature; Vector Laboratories, CA, USA), washed in $\mathrm{PB}$, and then incubated for 15 minutes in a diaminobenzidine solution (DAB) containing $0.1 \%$ 3,3-diaminobenzidine, $0.8 \%$ D-glucose and $0.016 \%$ ammonium chloride. Immunoreactivity was catalyzed by the addition of $0.2 \mu \mathrm{l} / \mathrm{ml}$ glucose oxidase aspergillus $(24 \mathrm{mg} / \mathrm{ml}, 307 \mathrm{U} / \mathrm{mg}$, Sigma-Aldrich, NSW, Australia). Brain sections were then washed in PB, mounted onto gelatin-coated slides, dehydrated, cleared in histolene, and coverslipped with Entellan (Proscitech, Kirwin, Australia), and assessed using an Olympus BX50 transmitted light microscope (Olympus, Shinjuku, Tokyo, Japan) or Axio Scan.Z1 slide scanner (Zeiss, Oberkochen, Germany).

Criteria for inclusion in final analysis was correct AAV and/or fiber placements determined after histology.

\section{Double fluorescence immunohistochemistry}

Rats were deeply anesthetized with sodium pentobarbital $(100 \mathrm{mg} / \mathrm{kg}$, i.p.; Virbac, NSW, Australia) and perfused transcardially with $200 \mathrm{ml}$ of $0.9 \%$ saline, containing heparin $(360 \mu \mathrm{l} / \mathrm{L})$ and sodium nitrite $(12.5 \mathrm{ml} / \mathrm{L})$, followed by $400 \mathrm{ml}$ of $4 \%$ paraformaldehyde in $0.1 \mathrm{M}$ phosphate buffer (PB), $\mathrm{pH} 7.4$. Brains were extracted from the skull and post fixed for one hour in the same fixative and then placed in $20 \%$ sucrose solution overnight. Brains were frozen and sectioned coronally at $40 \mu \mathrm{m}$ using a cryostat (Leica CM1950). Four serially adjacent sets of sections from the regions of interest were obtained from each brain and stored in $0.1 \%$ sodium azide in $0.1 \mathrm{M}$ PBS, $\mathrm{pH}$ 7.2. Free-floating sections were washed repeatedly in $0.1 \mathrm{M}$ PBS ( $\mathrm{pH} 7.2$ ), followed by a $2 \mathrm{~h}$ incubation in PBS (pH7.2) containing 10\% normal donkey serum (NDS) and $0.2 \%$ Triton $\mathrm{X}-100$. Sections were then incubated in the primary antibodies diluted in $0.1 \mathrm{M}$ PBS ( $\mathrm{pH} 7.2$ ) containing $0.1 \%$ sodium azide, $2 \%$ NHS and $0.2 \%$ Triton X-100, for $48 \mathrm{~h}$ at room temperature, with gentle agitation. The primary antibodies used were sheep anti TH (1:1000; Sheep AntiTyrosine Hydroxylase Polyclonal Antibody; Cat \# PA1-4679; 
RRID: AB 561880; ThemoFisher Scientific, MA, USA) and rabbit antieGFP (1:1000; Rabbit anti eGFP Polyclonal Antibody; Cat\#A-11122; RRID: AB_221569; ThemoFisher Scientific, MA, USA). After washing off unbound primary antibodies, sections were then incubated for $4 \mathrm{hr}$ at room temperature in secondary antibodies diluted in $0.1 \mathrm{M} \mathrm{PBS}(\mathrm{pH} 7.2)$ containing $2 \%$ NHS and $0.2 \%$ Triton X-100 (PBST-X). ). The secondary antibodies used were Alexa 488 donkey anti rabbit (1:500; Donkey antiRabbit IgG $(\mathrm{H}+\mathrm{L})$ Highly Cross-Adsorbed Secondary Antibody, Alexa Fluor 488; Cat\# A-21206; RRID: AB_2535792; ThemoFisher Scientific, MA, USA) and Alexa 594 donkey anti goat (1:500; Donkey anti-Goat IgG $(\mathrm{H}+\mathrm{L})$ Cross-Adsorbed Secondary Antibody, Alexa Fluor 594; Cat\# A-11058; RRID: AB_2534105; ThemoFisher Scientific, MA, USA). After washing off unbound secondary antibodies sections were mounted onto gelatin-treated slides and coverslipped with Permafluor mounting medium (Thermofisher Scientific, MA, USA). Fluorescent images were taken by Olympus BX53 upright microscope (Olympus, Shinjuku, Tokyo, Japan).

\section{Statistical Analyses}

\section{Inclusion criteria}

The criteria for inclusion in final analyzes were correct AAV and fiber placements as determined after histology, so animals were excluded if either AAV or fiber optic cannulae were misplaced. Data in figures are represented as mean \pm SEM unless otherwise stated. Group sizes were based on past experience with these preparations showing that they were sufficient to detect large $(\mathrm{d}=0.8)$ effect sizes in behavioral studies with at least $80 \%$ power. Group numbers used for analyzes in each experiment are indicated at two locations: (1) under the subheadings of behavioral procedures above; (2) in the main results text.

\section{Behavior}

Our primary behavioral dependent variables were numbers of active nosepokes, inactive nosepokes, and distance travelled (locomotor activity). These were analyzed by means of ANOVA and analyzes involving repeated measures adopted a multivariate approach (Harris, 2004). All analyzes partitioned variances into main effect and interaction terms using Psy Statistical Package (Bird, 2004).

\section{Fiber Photometry}

For fiber photometry, the primary dependent variables were $\mathrm{Ca} 2+$ or dopamine transients around nosepokes and magazine entries during training (sessions 2 and 10), extinction (session 1), extinction test (ABB), renewal test $(\mathrm{ABA})$, and reacquisition. These data were analyzed using custom MATLAB scripts.

Specifically, for gCaMP experiments, $\mathrm{Ca} 2+$ dependent and $\mathrm{Ca} 2+$ independent (isosbestic) signals during recording sessions were extracted and downsampled (15.89 samples/sec); signals around logged disconnections were removed prior to further signal processing. The isosbestic signal was regressed onto the $\mathrm{Ca} 2+$-dependent signal to create a fitted isosbestic signal and a fractional fluorescence signal $\Delta \mathrm{F} / \mathrm{F}$ was calculated via subtracting fitted $405 \mathrm{~nm}$ signal from $465 \mathrm{~nm}$ channels, and then dividing by the fitted $405 \mathrm{~nm}$ signal. This produces a motionartifact-corrected $\mathrm{Ca} 2+$ signal with a mean of $\sim 0$. Signal-to-noise was further boosted via filtering after contributions of low and high frequency components were determined via fast fourier transform; $\Delta \mathrm{F} / \mathrm{F}$ signal was convolved over 90sec (high-pass filtered) and then low-pass filtered at $2 \mathrm{~Hz}$.

$\Delta \mathrm{F} / \mathrm{F}$ within a time window around events was compiled and averaged for each trials To determine significant event-related transients within this window, a bootstrapping confidence interval (CI) procedure $(95 \%$ CI, 1000 bootstraps) was used (Jean-Richard-dit-Bressel et al., 2020). A distribution of bootstrapped $\Delta \mathrm{F} / \mathrm{F}$ means was generated by randomly resampling from trial $\Delta \mathrm{F} / \mathrm{F}$ waveforms, with replacement, for the same number of trials. A confidence interval was obtained per timepoint using the 2.5 and 97.5 percentiles of the bootstrap distribution, which was then expanded by a factor of $\operatorname{sqrt}(\mathrm{n} /(\mathrm{n}-1))$ to adjust for narrowness bias. Significant transients were defined as periods whose $95 \%$ CI did not contain 0 continuously (minimum 1/2sec).

A similar analysis procedure was used for dLight experiments, signals $(465 \mathrm{~nm}, 405 \mathrm{~nm})$ were downsampled and processed (logged disconnections removed, $\Delta \mathrm{F} / \mathrm{F}$ obtained using fitted isobestic). Then, signals were low-pass filtered at $3 \mathrm{~Hz}$ (significant transients minimum $=$ $1 / 3 \mathrm{sec}$ ) instead of $2 \mathrm{~Hz}$, due to the faster dynamics of dLight 1.1 compared to gCaMP.

Waveform kernels were obtained by normalising each trial waveform according to its sum square deviation from 0 and were used for further analysis. This approach to normalisation preserves the baseline of the waveform and allows interpretation of the mean kernel when it is different from 0 .

\section{Representational similarity analysis}

Representational similarity analysis (RSA; Kriegeskorte and Bandettini, 2008) is a modality-independent way of comparing activity patterns. To this end, the dissimilarity of two peri-event kernel waveforms was quantified using correlation distance ( 1 - Pearson correlation) of the mean trial kernel waveforms ( $\pm 3 \mathrm{~s}$ around events). A first order representational dissimilarity matrix (RDMs) was formed from the pairwise correlation distances, indicating the degree to which each pair of waveforms are similar/dissimilar. First order RDMs representing dissimilarity in activity patterns to Nosepoke + across session for each brain region (Figure 2D,2E, Figure 3D, 3E, 3F) were generated using custom MATLAB scripts. A cross-experiment first order RDM was constructed using the same methodology (correlation distance of perievent activity), using the mean Nosepoke+ kernel across sessions and brain regions as inputs. The dissimilarity in the dissimilarity matrices were assessed using second order RSA (Kriegeskorte and Bandettini, 2008; Figure 4). Instead of comparing neural activity, second order RSA compares RDMs. By abstracting from underlying data, second order RSA is modality independent and can be used to compare similarities in disparate data types (e.g. fMRI, neuron spiking). For dissimilarity of different brain region activity profiles (Figure 4B), the correlation distance ( 1 - Spearman correlation) between single brain region RDMs (cross-session RDM) was calculated. For dissimilarity of different session activity profiles (Figure 4C), the correlation distance (1 Spearman correlation) between single session RDMs (cross-region RDM) was calculated.

To visualise first and second order similarities/dissimilarities between pairs of condition, correlation distances were also conveyed using multidimensional scaling. Coordinates were obtained using (MATLAB mdscale function $(\mathrm{p}=2$, criterion $=$ metricsstress $)$. Across graphs, $\mathrm{S}$ Stress was consistently below 0.2 , indicating a fair fit of the data. 


\section{Results}

\section{Ventral tegmental area TH neurons mediate different forms of relapse}

First, we studied the causal roles of VTA ${ }^{\mathrm{TH}}$ neurons in relapse. To do this, we expressed the cre-dependent inhibitory hM4Di DREADD) $(n=8)$ or enhanced yellow fluorescent protein (eYFP) $(n=6)$ in the VTA of THCre rats (Liu et al., 2016) (Figure S1A, C), then trained rats to respond for alcoholic beer in a distinctive context (A). Responses on one nosepoke (active) caused delivery of alcoholic beer to a magazine cup whereas responses on a second nosepoke (inactive) did not. In each experiment, rats readily learned to self-administer (Table S1). Then we extinguished this behavior in a second, distinctive context (B) where responses did not earn alcohol. In each experiment, responding was reduced by extinction training (Table $\mathbf{S 1}$ ).

We tested for two forms of relapse: renewal (context-induced reinstatement) (Crombag and Shaham, 2002; Hamlin et al., 2007; Bouton and Todd, 2014) and reacquisition (Willcocks and McNally, 2011). For renewal, rats were tested in the extinction context (extinction, ABB test) and in the training context (ABA) (Figure 1A). There was no alcohol available during these tests and rats were injected with the hM4Di ligand clozapine $(0.1 \mathrm{mg} / \mathrm{kg}$, i.p. $)$. Rats refrained from alcohol-seeking in the extinction context but relapsed to alcohol-seeking in the training context (context main effect: $\mathrm{F}(1,12)=52.91, \mathrm{p}<0.001$; nosepoke main effect $\mathrm{F}(1,12)=72.77, \mathrm{p}<0.001$; context $\mathrm{x}$ nosepoke interaction, $\mathrm{F}(1,12)=$ 39.97, $\mathrm{p}<0.001$ ) (Figure 1B), showing renewal (context-induced reinstatement) of alcohol-seeking. VTA TH chemogenetic inhibition reduced responding on $\mathrm{ABA}$ test (main effect group $\mathrm{F}(1,12)=13.01$, $\mathrm{p}$ $=0.004$; group $\mathrm{x}$ context interaction $\mathrm{F}(1,12)=5.78, \mathrm{p}=0.033$; group $\mathrm{x}$ nosepoke $F(1,12)=8.09, p=0.015$ interaction) but had no effect on locomotor function (Figure S1D).

Next we re-trained rats to self-administer alcohol in a single session to model the relapse provoked by contingent re-exposure to alcohol. In humans this causes a rapid return to pre-abstinence levels of drinking that is resistant to pharmacotherapy (Marlatt and Donovan, 2005). In rodents, a similar return to pre-extinction levels of self-administration is observed (Willcocks and McNally, 2011) (Figure 1C) (nosepoke main effect: F $(1,12)=82.62, \mathrm{p}<0.001)$ and this was reduced by chemogenetic VTA TH inhibition (main effect group $\mathrm{F}(1,12)=16.09, \mathrm{p}=0.002$; group $\mathrm{x}$ nosepoke interaction $\mathrm{F}(1,12)=15.99, \mathrm{p}=0.002)$.

In order to exclude the possibility that clozapine as the hM4Di ligand (Gomez et al., 2017) interacted with the effects of alcoholic beer during reacquisition, we expressed the cre-dependent inhibitory KORD DREADD (Marchant et al., 2016; Vardy et al., 2015) $(n=8)$ or enhanced yellow fluorescent protein (eYFP) $(n=6)$ in the VTA of TH-Cre rats and inhibited TH neurons via injection of SalB (15 ml/kg, i.p.). KORD chemogenetic inhibition of VTA TH neurons also reduced relapse during reacquisition (main effect group $\mathrm{F}(1,14)=5.26, \mathrm{p}=0.038$; group $\mathrm{x}$ nosepoke interaction $\mathrm{F}(1,14)=4.55 \mathrm{p}=0.051$ overall; $\mathrm{F}(1,14)=9.647$, $\mathrm{p}=0.008$ first $10 \mathrm{~min}$ ). (Figure 1D).

Activity of VTA TH neurons during self-administration and relapse Next we used fibre photometry (Gunaydin et al., 2014) to determine when during self-administration and relapse VTA TH neuron activity was important and whether this varied across the medial-lateral extent of the VTA (Lammel et al., 2011; Lammel et al., 2013; Yang et al., 2018) (Figure 2A). We expressed cre-dependent gCaMP6f and implanted optical fibres above VTA of TH-cre rats $(n=24)$. Using the lateral edge of the fasciculus retroflexus as a boundary (Ikemoto, 2007), histology showed that cannulae were located above medial $(n=8)$ or lateral $(n=$ 16) VTA (Figure S2A). $\mathrm{Ca}^{2+}$ transients were recorded during early and late self-administration, the first day of extinction training, and tests (ABA renewal, ABB extinction, reacquisition) (Figure 2B).

We used a bootstrap 95\% confidence interval procedure (bCI) (JeanRichard-dit-Bressel et al., 2020) to analyse perievent $( \pm 3 \mathrm{~s}) \mathrm{df} / \mathrm{f}$ waveforms and detected significant $\mathrm{Ca}^{2+}$ transients associated with nosepokes and magazine entry. Transients were greater for active nosepokes that turned on the pump causing delivery of alcoholic beer (Nosepoke + ) (Figure 2C) and magazine entries after a Nosepoke+ (Figure S2B) compared to active nosepokes or magazine entries at other times (Nosepoke- and Magazine-). Transients increased across the course of self-administration training, reduced during extinction, and were restored during renewal and reacquisition. There were obvious differences between mVTA and IVTA. There were negative transients in mVTA during early acquisition but positive transients in IVTA. By late acquisition there were positive transients in both regions. There were transients in IVTA, but not mVTA, during extinction and renewal. There were transients in both regions during reacquisition. Similar findings were observed for Magazine+ behavior (Figure S2B).

These findings show that relapse is associated with recruitment of VTA TH neurons. They suggest that different forms of relapse might be dissociable within VTA, with renewal linked to IVTA and reacquisition to both mVTA and IVTA. To test this, we expressed Cre-dependent eNpHR3.0 in VTA of TH Cre $+(n=12)$ or Cre- $(n=8)$ rats and targeted optical fibres towards either medial $(\mathrm{n}=6 \mathrm{TH}-\mathrm{Cre}+)$ or lateral $(\mathrm{n}=6$ TH-Cre + ) VTA to limit optogenetic inhibition to these regions (Figure S3A). We silenced VTA TH neurons for $10 \mathrm{~s}$ only during Nosepoke+ behavior to inhibit these neurons during the time we had observed significant $\mathrm{Ca}^{2+}$ transients. Consistent with our photometry results, mVTA inhibition reduced reacquisition whereas IVTA inhibition reduced reacquisition and renewal (Figure S3B).

Event-related analyses link VTA TH activity to discrete alcohol-seeking and relapse behaviors. Indeed, these identified different roles for mVTA and IVTA that we confirmed via optogenetic inhibition. However, these analyses do not show whether or how VTA TH activity changes across self-administration, extinction, and relapse. To answer this, we compared VTA gCaMP activity patterns across different stages of the experiment using Representational Similarity Analyses (RSA) (Kriegeskorte and Kievit, 2013; Kriegeskorte et al., 2008a; Kriegeskorte et al., 2008b; Nili et al., 2014). We computed normalized $\mathrm{Ca}^{2+}$ waveforms for each stage (Figure S2C), correlated these across each pair of conditions, and computed correlation distance ( 1 - Pearson correlation) between pairs to measure their dissimilarity ( 0 for perfect correlation, 1 for no correlation, 2 for perfect anticorrelation). This complements single event analysis because it assesses dissimilarity between VTA TH activity across the experiment. Correlation distances were assembled into a first-order dissimilarity matrix (RDM) reporting dissimilarity of mVTA and IVTA TH activity signatures across the experiment (Figure 2D, E). Multidimensional scaling visualized these dissimilarities. There was pronounced change in the mVTA TH response across self-administration because mVTA activity in early and late self-administration was highly dissimilar. Moreover, in mVTA, both forms of relapse were more similar to established than early self-administration. For IVTA, there was less change with acquisition and different forms of relapse similar to each other. 
A AAV5 DIO::hM4Di

A AAV5 DIO:::KORD
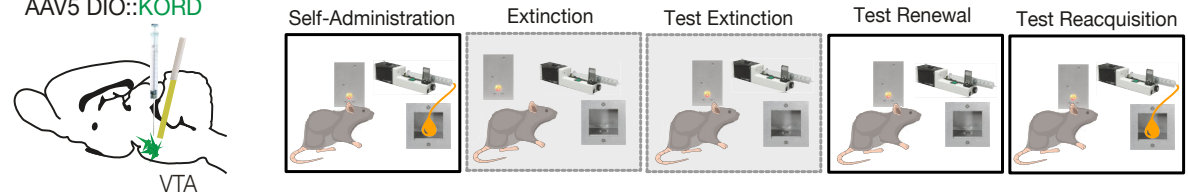

Extinction (ABB)

Renewal (ABA)

B
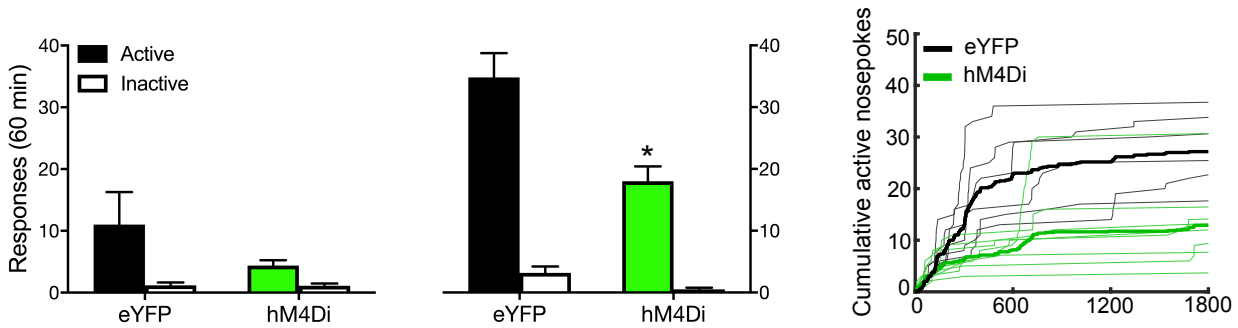

C
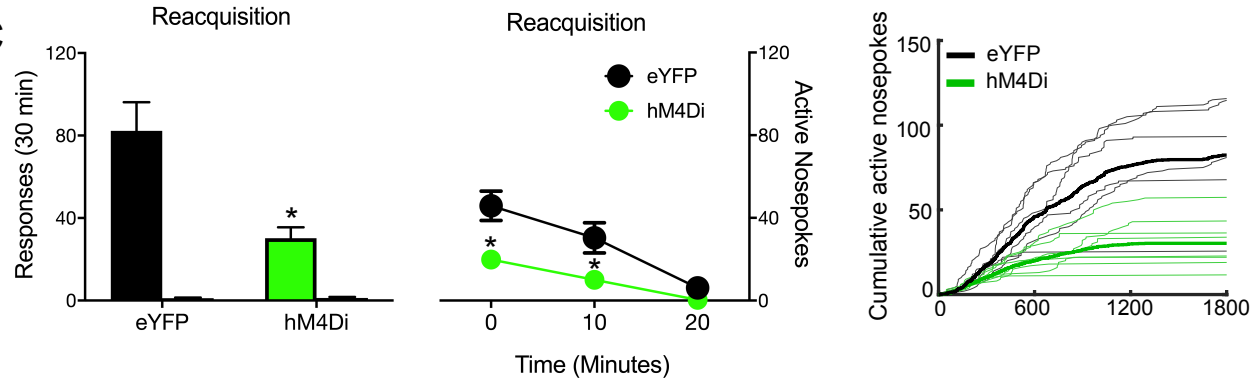

D

Reacquisition

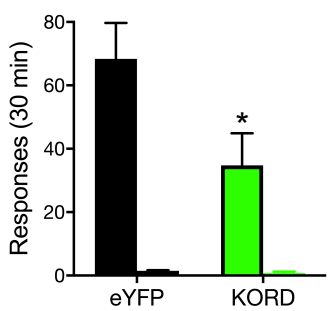

Reacquisition
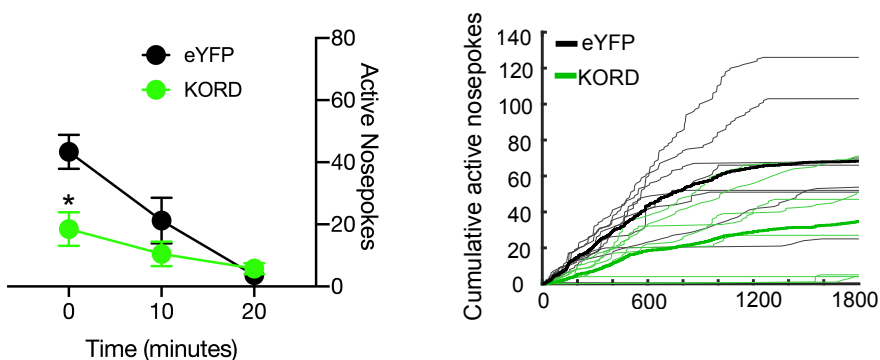

Figure 1. VTA TH neurons mediate relapse (A) Cre-dependent inhibitory DREADDs were applied to the VTA. Rats were trained and tested in an ABA renewal procedure and also tested for reacquisition. (B) hM4Di chemogenetic inhibition of VTA TH neurons reduced responding during ABA renewal (context-induced reinstatement) of alcohol seeking. (C) hM4Di chemogenetic inhibition of VTA TH neurons reduced reacquisition, with data shown as total and in 10 min time bins. (D) KORD chemogenetic inhibition of VTA TH neurons also reduced reacquisition, with data shown as total and in $10 \mathrm{~min}$ time bins. Raw data are shown for all individual rats as cumulative functions. All analyses were ANOVAs. ${ }^{*} \mathrm{p}<.05$. 
bioRxiv preprint doi: https://doi.org/10.1101/2020.03.06.981605; this version posted March 8, 2020. The copyright holder for this preprint (which was not certified by peer review) is the author/funder. All rights reserved. No reuse allowed without permission.

A
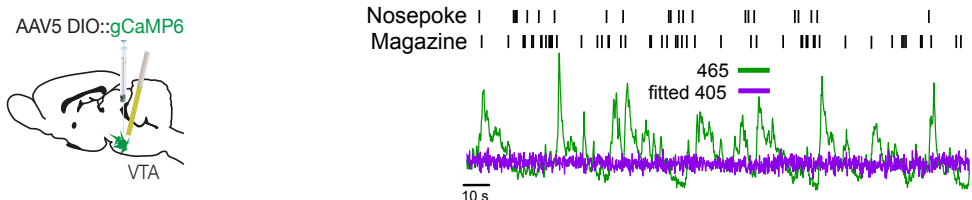

B
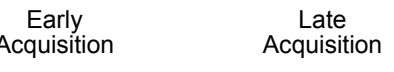

$$
\text { Extinction }
$$

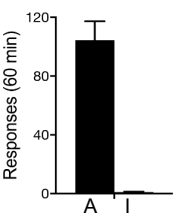

C
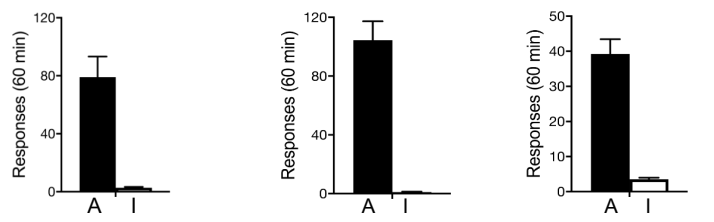

Renewal

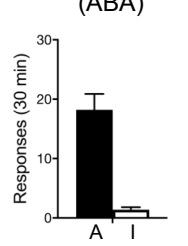

Reacquisition
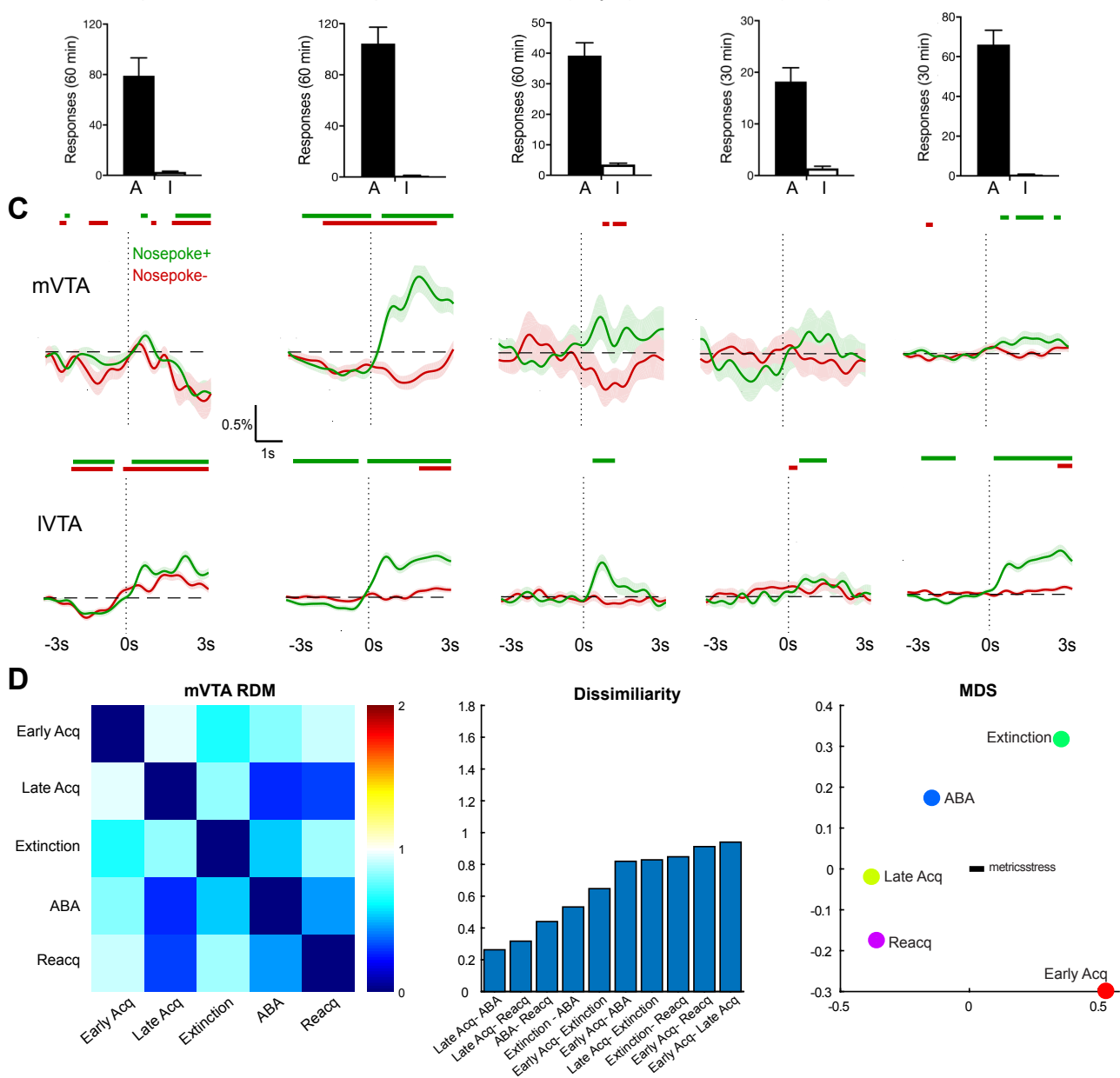

E
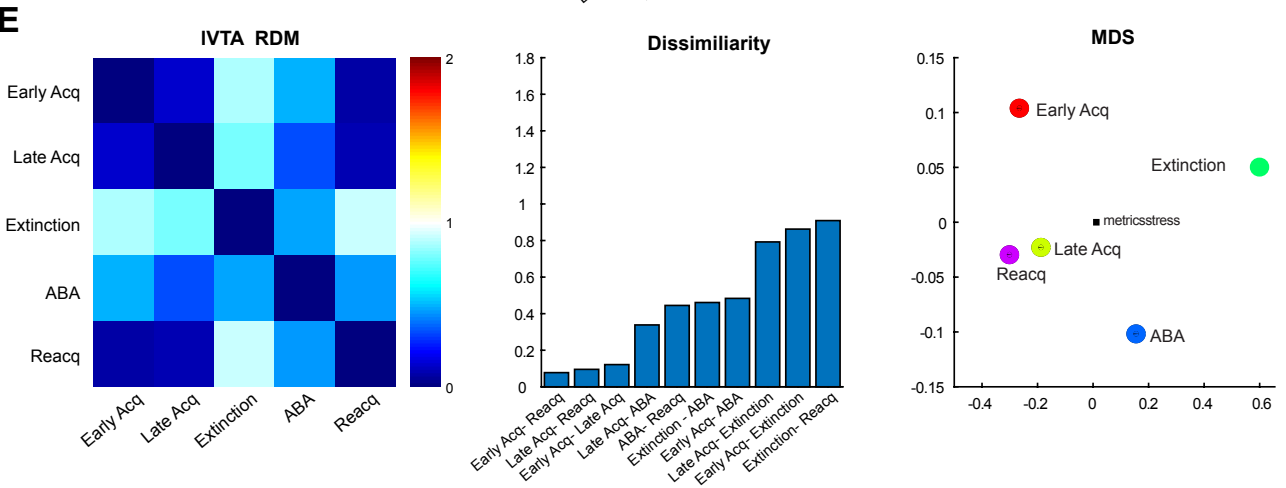

Figure 2. Activity of VTA TH neurons during relapse. (A) Cre-dependent gCaMP6 $\mathrm{f}$ was applied to the VTA and rats were trained and tested in an ABA renewal procedure and for reacquisition. A representative trace from recording is shown. (B) Mean \pm SEM active, $A$, and inactive, $I$, nosepokes from the five recording sessions. (C) Mean \pm SEM calcium transients in VTA TH neurons $\pm 3 \mathrm{~s}$ around Nosepoke+ (active nosepokes that triggered the pump) and Nosepoke- (active nosepokes at other times) for mVTA and IVTA. Coloured bars above traces show periods (with minimum consecutive threshold) of significant difference from 0 as defined by $95 \%$ confidence intervals. (D) and (E), Representational dissimilarity matrix (RDM) for mVTA and IVTA (0 for perfect similarity, 1 for no similarity, 2 for perfect dissimilarity) with multidimensional scaling (MDS) visualisation whereby distances reflect dissimilarity. 


\section{Dopamine release in the ventral striatum during self-administration and relapse}

D1 dopamine receptors (Crombag et al., 2002), especially those in the nucleus accumbens (Acb) (Bossert et al., 2007; Chaudhri et al., 2009; Hamlin et al., 2007), are important for relapse and we confirmed this (Figure S4A-C). Single unit (Carelli and Deadwyler, 1994; Carelli and Ijames, 2000; Chang et al., 1998; Chang et al., 2000; Janak et al., 1999; Woodward et al., 2000) and fast-scan cyclic voltammetry (Phillips et al., 2003; Stuber et al., 2005a; Stuber et al., 2005b) recordings strongly link activity in the nucleus accumbens core (AcbC) to drug seeking, but the spatiotemporal profiles of dopamine release across the Acb during relapse are unknown as is whether these differ across forms of relapse. We used dLight photometry (Patriarchi et al., 2018) to address this (Figure 3A). We expressed dLight1.1 in Acb $(\mathrm{N}=18)$ and implanted optical fibers above medial accumbens shell (AcbShM, $n=6)$, AcbC, $n$ $=7$, or lateral accumbens shell $(\mathrm{AcbShL})(\mathrm{n}=5)$ of Long-Evans rats (Figure S4D). Dopamine transients were recorded during early and late self-administration, early extinction training, and relapse (Figure 3B).

$95 \%$ bCI analyses of normalized peri event ( \pm 3 s) dLight waveforms detected significant dopamine transients for Nosepoke+ and Magazine+ (Figure 3C, Figure S4E) that depended on Acb subregion and the stage of the experiment. For AcbShM, there were reductions in dopamine transients early in acquisition replaced by positive transients in late selfadministration and these were preserved during the remaining stages. This is similar to the profile observed for mVTA gCaMP. For AcbC, there were positive dopamine transients across each stage, similar to the profile observed for IVTA gCaMP. For AcbShL, positive transients emerged across self-administration, were lost across extinction, and restored only during reacquisition.

First-order RDMs and multidimensional scaling captured dissimilarity of Acb dopamine responses across sessions. There was pronounced change in the AcbShM dopamine response because early self-administration was dissimilar to all other stages except late self-administration. (Figure 3D). There was strong similarity between AcbC dopamine responses across all stages except extinction (Figure 3E). In marked contrast, AcbShL dopamine responses were highly dissimilar across the experiment, with only late self-administration and reacquisition similar (Figure 3F).

\section{Identifying and comparing mesolimbic dopamine signatures}

Our results show recruitment across the mesolimbic dopamine system, with distinct profiles of activity within and across distinct compartments of this system. These findings raise fundamental questions about how activity in these distinct compartments relate to each other and how relapse is assembled from these distinct spatiotemporal activity profiles.

We used RSA on our complete photometry dataset to answer these questions. RSA quantitatively assesses the extent to which the dopamine activity signatures (i.e. VTA TH gCaMP and Acb dLight) across brain regions or behavioral stages are alike (Kriegeskorte and Kievit, 2013; Kriegeskorte et al., 2008b; Nili et al., 2014). We computed a first-order $\mathrm{RDM}$ for each brain region from early self-administration to relapse (Figure 4A). This reports dissimilarity between pairs of activity patterns. Then, we computed a second-order RDM across the first-order RDM for each brain region (Figure 4B), reporting dissimilarity between pairs of values in the first-order RDM (i.e. dissimilarity between brain regions), where dissimilarity is defined as the correlation distance (1 - Spearman correlation). Because the second-order RDMs compare first-order RDMs, it overcomes the problem of correspondency between spatiotemporally distinct activity profiles. Again, to aid interpretation, we used multidimensional scaling to visualize dissimilarity of these secondorder RDMs.

Consistent with known connectivity (de Jong et al., 2019; Lammel et al., 2011; Lammel et al., 2013; Yang et al., 2018), the Region RDM (Figure 4B) showed that across self-administration to relapse, the signatures of IVTA and AcbC as well as mVTA and AcbShM were highly similar. Surprisingly, the signatures of the three Acb regions were highly dissimilar. In fact, there was more similarity between individual VTA and Acb subregions than among the Acb subregions themselves.

Finally, we computed second-order RDMs across experimental stage to identify and compare mesolimbic dopamine signatures for selfadministration stages. The second order Behavior RDM (Figure 4C) identified four key findings. First, there was a change in the mesolimbic dopamine signature from early to late self-administration. Second, there were distinct mesolimbic dopamine signatures for the two forms of relapse. Third, the signature of reacquisition was similar to the signature of late self-administration. Fourth, there was little meaningful relationship between mesolimbic dopamine signatures when animals could only use environmental cues to guide their behavior because the outcome was absent (i.e. Extinction and ABA).

\section{Discussion}

It is well established that there are heterogenous response profiles across the mesolimbic dopamine system that serve distinct functions (Cohen et al., 2012; de Jong et al., 2019; Heymann et al., 2019; Lammel et al., 2008; Lammel et al., 2011; Lammel et al., 2013; Mohebi et al., 2019; Saunders et al., 2018; Tian et al., 2016; Watabe-Uchida et al., 2012). Our findings support this. We show considerable diversity in spatiotemporal activity profiles across the VTA and ventral striatum during self-administration and two forms of relapse to alcohol-seeking. Moreover, we show that this activity causes relapse during renewal and reacquisition.

Although the isolated response profiles of individual compartments of the mesolimbic dopamine system are interesting (e.g., Figures $2 \mathrm{C}, 3 \mathrm{C}$ ), the challenge is to move beyond individual profiles to understand how they orchestrate complex behaviors. This has proved difficult because it requires comparison of response profiles across different brain regions and different measures, in the same or different animals. This problem is not solved by multisite recording in the same animals because these still require comparison of response profiles across different brain regions and/or different sensors. RSA overcomes this problem to reveal how different features of alcohol-seeking relate to different features of the mesolimbic dopamine response. It allowed us to summarise mesolimbic dopamine signatures of relapse.

Established alcohol self-administration was a period of striking conformity across the mesolimbic system. This conformity was not present during early self-administration and instead emerged across training. Extinction, on the other hand, was a fracture point in these signatures. The similarity in activity profiles that was so pronounced during late self-administration was lost during extinction, revealing functional segregation across the mesolimbic dopamine system. Overall, there was strong similarity between mVTA and AcbShM as well as between IVTA and AcbC, consistent with contemporary understanding of mesolimbic dopamine architecture (de Jong et al., 2019; Lammel et al., 2011; Lammel et al., 2013; Yang et al., 2018). The activity signature of AcbShL, on the other hand, was highly dissimilar to the rest of the ventral striatum. This aligns with anatomical (Ikemoto, 2007), functional 


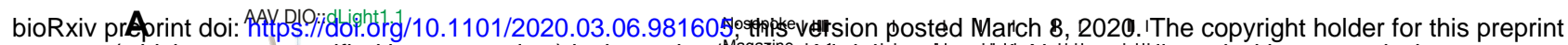

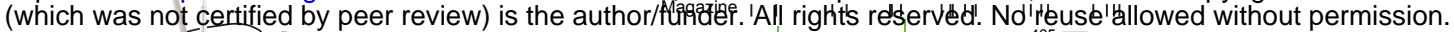

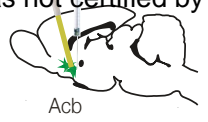

B
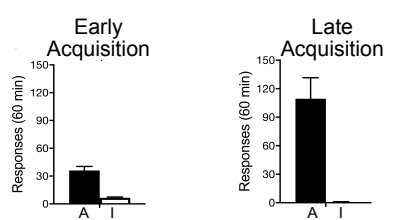

C

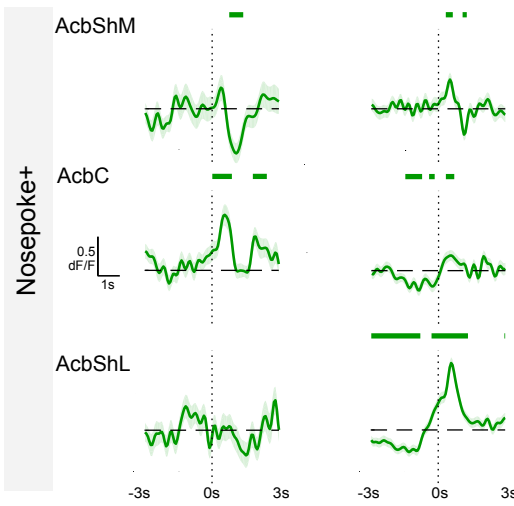

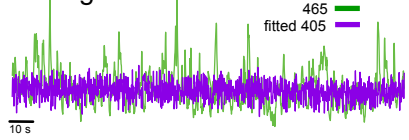
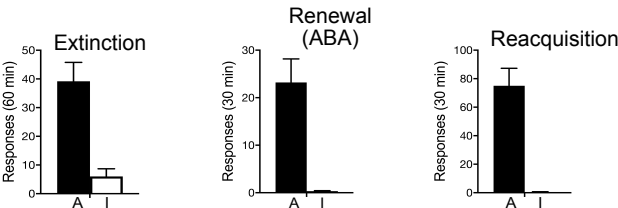

Mwintar

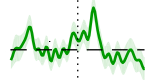

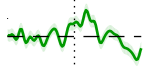

anditint

Antwath

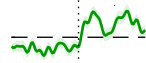

anditimat

artityp

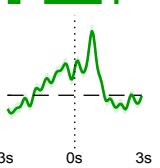

D
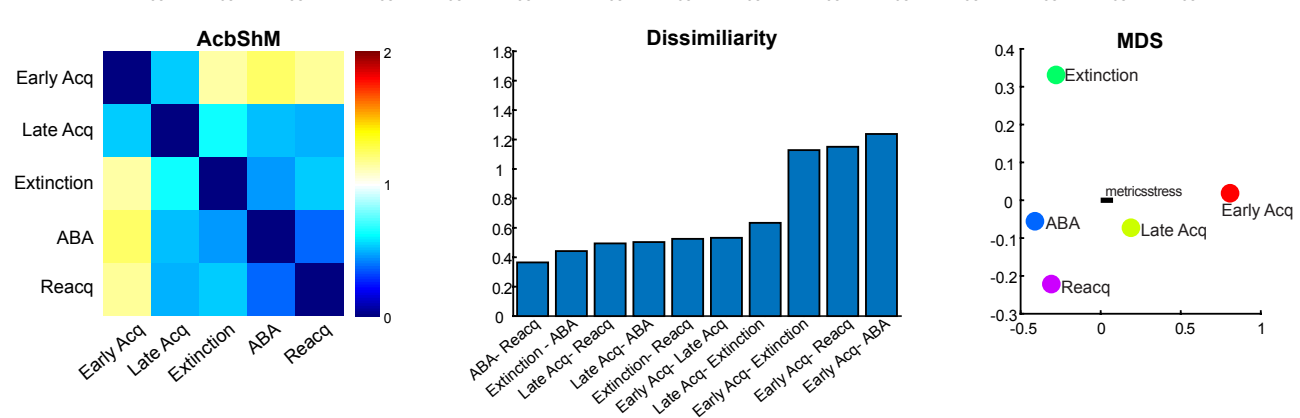

E

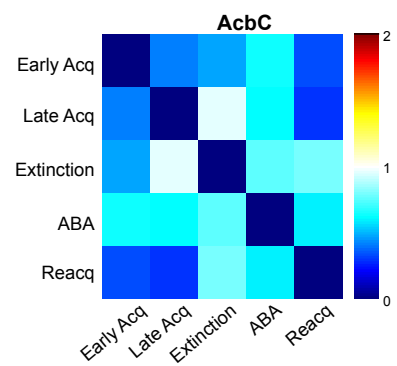

$\mathbf{F}$

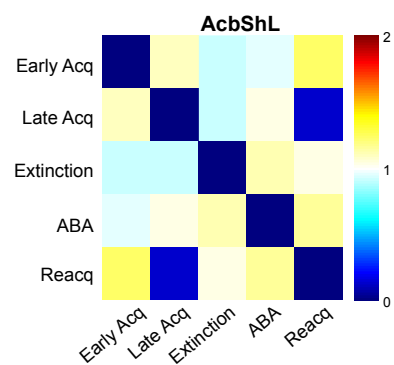

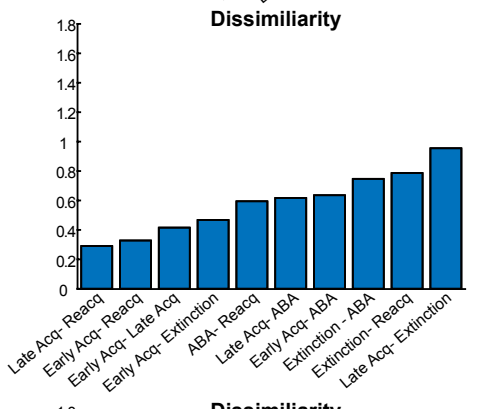

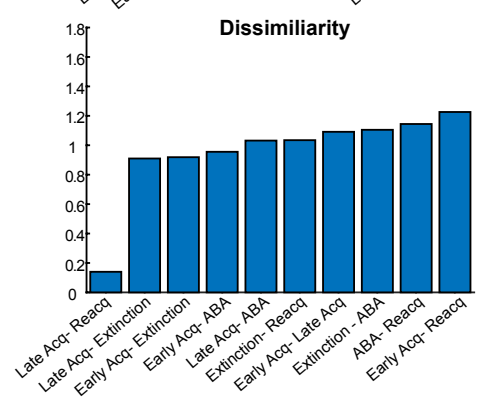

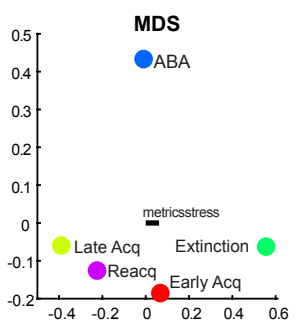

MDS

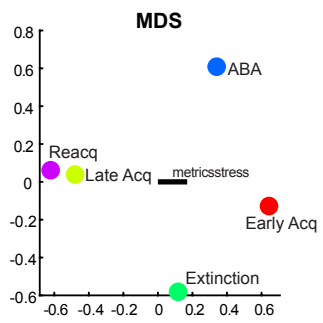

Figure 3. Dopamine transients in the ventral striatum. A) dLight was applied to AcbShM, AcbC, or AcbShL and rats were trained and tested in an $\mathrm{ABA}$ renewal procedure and for reacquisition. A representative recording trace is shown. (B) Mean \pm SEM active, $A$, and inactive, $I$, nosepokes from the five recording sessions. (C) Mean \pm SEM dopamine transients $\pm 3 \mathrm{~s}$ around Nosepoke+. Green bars above traces show periods (with minimum consecutive threshold) of significant difference from 0 as defined by $95 \%$ confidence intervals. (D - F), RDMs with multidimensional scaling (MDS) visualisation whereby distances reflect dissimilarity. 


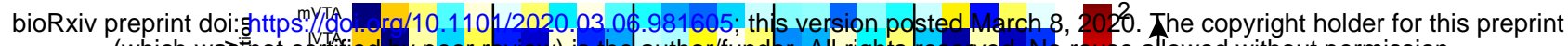

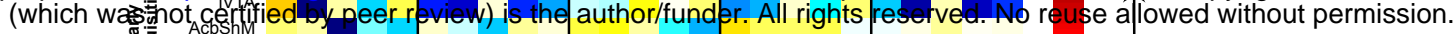

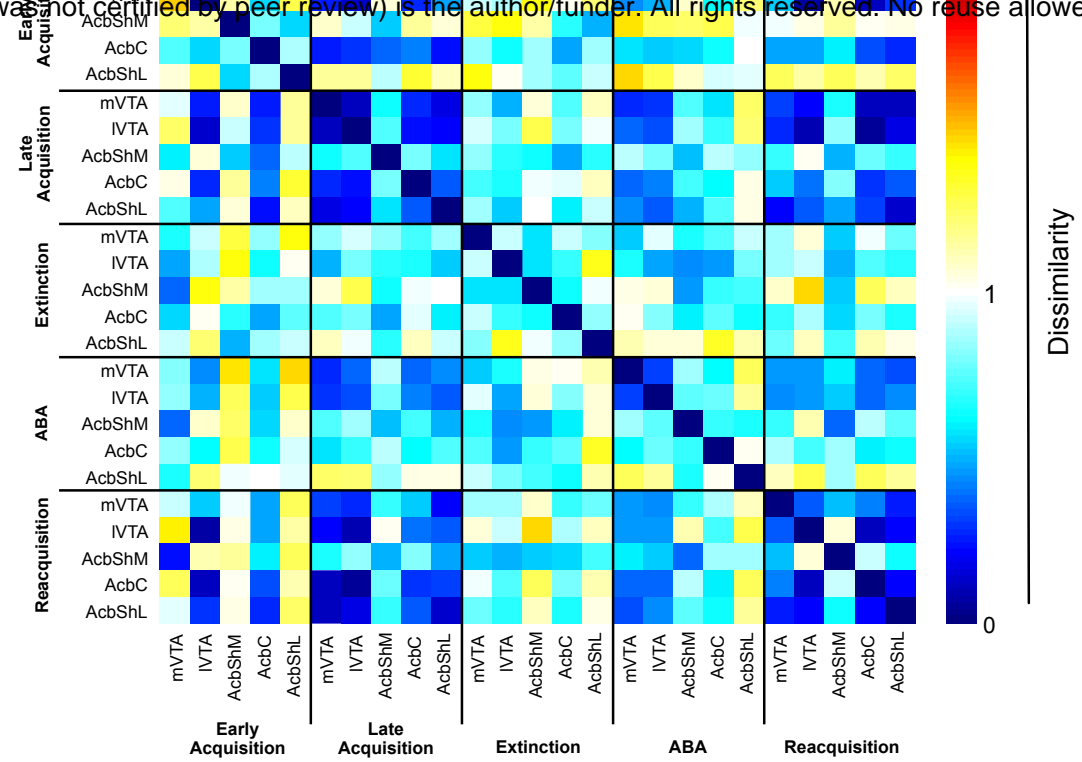

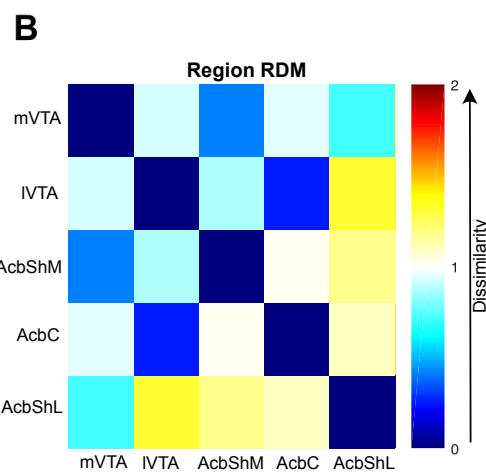

C

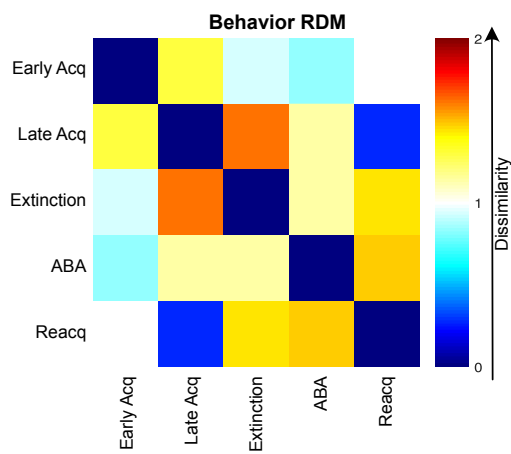

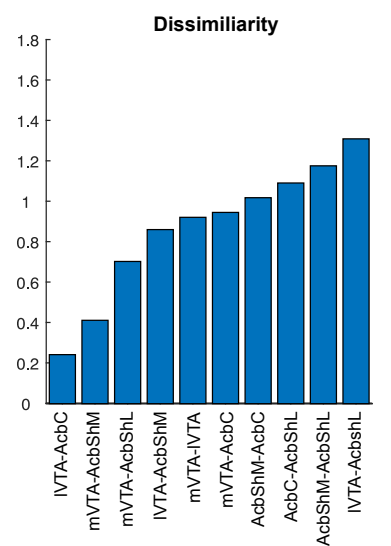
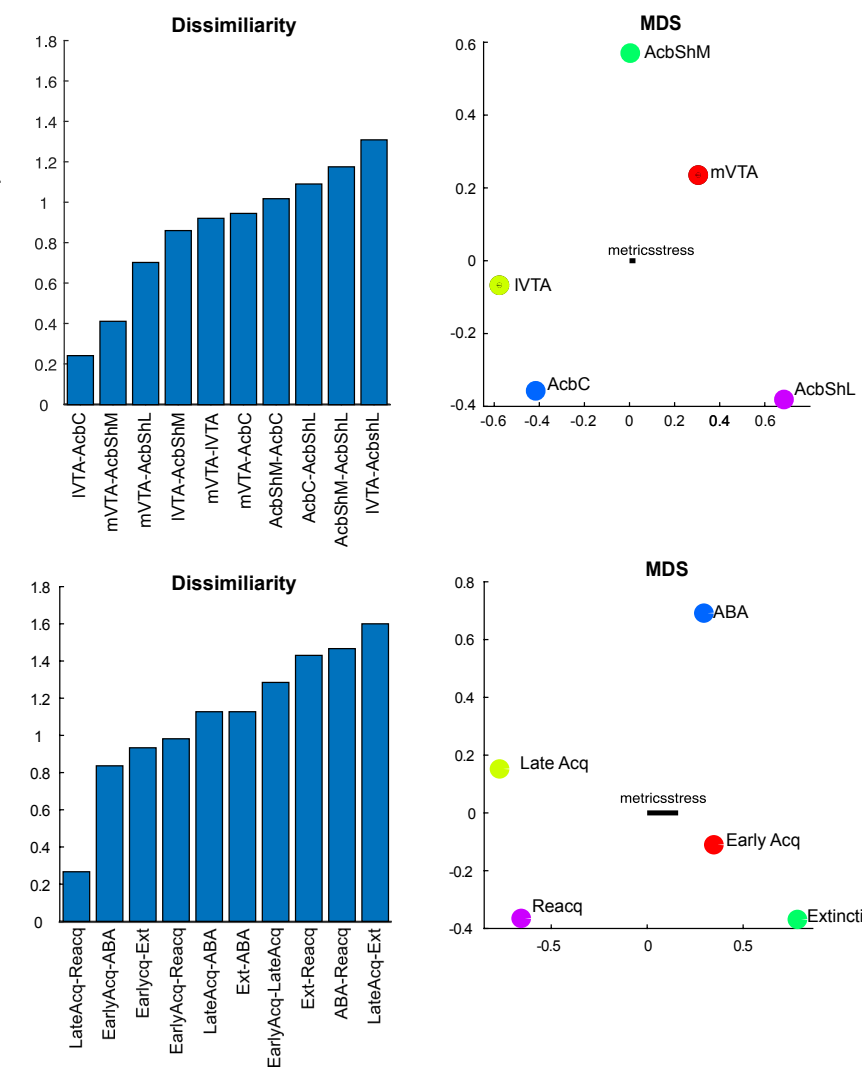

MDS

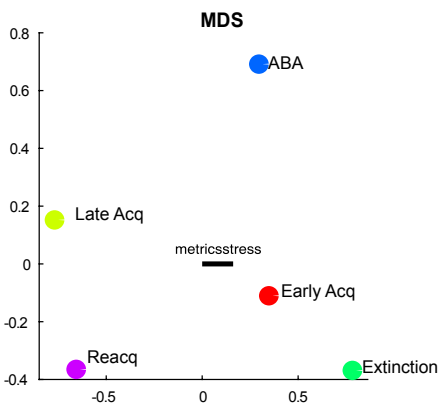

Figure 4. Representational similarity analysis. (A), First-order RDM showing correlation distances between all pairs of conditions. (B) Second order Brain RDM showing dissimilarity for each pair of brain regions, and MDS visualisation of these differences whereby distances reflect dissimilarity. (C) Second order Behavior RDM showing dissimilarity for each pair of behavioral self-administration stages, difference from RDM for each pair of behavioral conditions, and MDS visualisation of these differences. 
(Basso and Kelley, 1999; de Jong et al., 2019; Ikemoto et al., 2005), and cellular (Meredith et al., 1993) differences between AcbSh subregions, although it is worth noting that dopamine actions in both AcbShM and AcbShL are necessary for renewal of opiate seeking (Bossert et al., 2007).

Different forms of relapse have distinct mesolimbic dopamine signatures. This stands in marked contrast to influential theoretical (Bouton, 2002; Bouton, 2014; Bouton and Todd, 2014; Todd et al., 2014) and clinical (Marlatt, 1996; Stout et al., 1996) models. The mesolimbic dopamine signature for renewal was unique. It was dissimilar to selfadministration, extinction, and reacquisition. This was surprising because renewal shares key behavioral features with each of these other stages. For example, renewal involves return to the self-administration context, shares with extinction the use of environmental cues to guide behavior, and shares with reacquisition a return to responding after extinction. It is precisely the similarities between these different forms of relapse that have shaped contemporary theoretical and clinical understanding. Nonetheless, the mesolimbic dopamine signature of renewal was dissimilar to these and other stages of self-administration. Relapse initiated by contextual cues is distinctly represented by the mesolimbic dopamine system.

Reacquisition, on the other hand, was not distinctly represented. The mesolimbic dopamine signature of reacquisition was remarkably similar to late self-administration, showing that extinction did not return the mesolimbic dopamine system to a naive state. Rather, the mesolimbic dopamine signature that emerged across self-administration rapidly reappeared during reacquisition. This preservation or savings of the mesolimbic dopamine signature from late self-administration offers a powerful explanation for why relapse after contingent contact with alcohol is so difficult to prevent or treat (Anton et al., 2006; Marlatt and Donovan, 2005; Willcocks and McNally, 2014).

It remains to be discovered whether the dopamine signatures of other forms of relapse (cue-, stress-, priming) have the same or different features to those discovered here. Likewise, it remains to be discovered whether and how these signatures vary across different drugs of abuse. The RSA approach offers a powerful and straightforward way to answer these and related questions. Regardless, our findings that there are distinct mesolimbic dopamine signatures for different forms of relapse highlight the need for new theoretical models to better understand the mechanisms for relapse and to inform clinical approaches for preventing relapse.

\section{References}

Anton, R.F., O'Malley, S.S., Ciraulo, D.A., Cisler, R.A., Couper, D., Donovan, D.M., Gastfriend, D.R., Hosking, J.D., Johnson, B.A., LoCastro, J.S., et al. (2006). Combined Pharmacotherapies and Behavioral Interventions for Alcohol Dependence The COMBINE Study: A Randomized Controlled Trial. JAMA 295, 2003-2017.

American Psychiatric Association, (2013). Diagnostic and Statistical Manual of Mental Disorders (5th ed.) (Arlington, VA: American Psychiatric Publishing).

Basso, A.M., and Kelley, A.E. (1999). Feeding induced by GABAA receptor stimulation within the nucleus accumbens shell: Regional mapping and characterization of macronutrient and taste preference. Behavioral Neuroscience 113, 324-336.

Bird KD (2004) Analysis of variance via confidence intervals. London: Sage.

Bobadilla, A.-C., Heinsbroek, J.A., Gipson, C.D., Griffin, W.C., Fowler, C.D., Kenny, P.J., and Kalivas, P.W. (2017). Corticostriatal plasticity, neuronal ensembles, and regulation of drug-seeking behavior, Vol 235, 1 edn (Elsevier B.V.).

Bossert, J.M., Marchant, N.J., Calu, D.J., and Shaham, Y. (2013). The reinstatement model of drug relapse: recent neurobiological findings, emerging research topics, and translational research. Psychopharmacology 229, 453-476.

Bossert, J.M., Poles, G.C., Wihbey, K.A., Koya, E., and Shaham, Y. (2007). Differential effects of blockade of dopamine D1-family receptors in nucleus accumbens core or shell on reinstatement of heroin seeking induced by contextual and discrete cues. The Journal of Neuroscience 27, 12655-12663

.Bouton, M.E. (2002). Context, ambiguity, and unlearning: Sources of relapse after behavioral extinction. Biological Psychiatry 52, 976-986.

Bouton, M.E. (2014). Why behavior change is difficult to sustain. Preventative Medicine 68, 29-36.

Bouton, M.E., and Todd, T.P. (2014). A fundamental role for context in instrumental learning and extinction. Behavioural Processes 104, 13-19.

Carelli, R.M., and Deadwyler, S.A. (1994). A comparison of nucleus accumbens neuronal firing patterns during cocaine self-administration and water reinforcement in rats. Journal of Neuroscience 14, 7735-7746.

Carelli, R.M., and Ijames, S.G. (2000). Nucleus accumbens cell firing during maintenance, extinction, and reinstatement of cocaine self-administration behavior in rats. Brain Research 866, 44-54.

Chang, J.Y., Janak, P.H., and Woodward, D.J. (1998). Comparison of mesocorticolimbic neuronal responses during cocaine and heroin selfadministration in freely moving rats. The Journal of Neuroscience 18, 3098 3115.

Chang, J.Y., Janak, P.H., and Woodward, D.J. (2000). Neuronal and behavioral correlations in the medial prefrontal cortex and nucleus accumbens during cocaine self-administration by rats. Neuroscience 99, 433-443.

Chaudhri, N., Sahuque, L.L., and Janak, P.H. (2009). Ethanol seeking triggered by environmental context is attenuated by blocking dopamine D1 receptors in the nucleus accumbens core and shell in rats. Psychopharmacology 207, 303314.

Cohen, J.Y., Haesler, S., Vong, L., Lowell, B.B., and Uchida, N. (2012). Neurontype-specific signals for reward and punishment in the ventral tegmental area. Nature 482, 85-88.

Crombag, H.S., Grimm, J.W., and Shaham, Y. (2002). Effect of dopamine receptor antagonists on renewal of cocaine seeking by reexposure to drug-associated contextual cues. Neuropsychopharmacology 27, 1006-1015.

de Jong, J.W., Afjei, S.A., Pollak Dorocic, I., Peck, J.R., Liu, C., Kim, C.K., Tian, L., Deisseroth, K., and Lammel, S. (2019). A neural circuit mechanism for encoding aversive stimuli in the mesolimbic dopamine System. Neuron 101, 133-151 e137.

Everitt, B.J., Belin, D., Economidou, D., Pelloux, Y., Dalley, J.W., and Robbins, T.W. (2008). Review. Neural mechanisms underlying the vulnerability to develop compulsive drug-seeking habits and addiction. Philosophical transactions of the Royal Society of London: Series B, Biological Sciences 363, 3125-3135.

Gibson, G.D., Prasad, A.A., Jean-Richard Dit Bressel, P., Yau, J.O.Y., Millan, E.Z., Liu, Y., Campbell, E.J., Lim, J., Marchant, N.J., Power, J.M., et al. (2018). Distinct accumbens shell outputpPathways promote versus prevent relapse to alcohol seeking. Neuron 98, 512-520.e516.

Gomez, J.L., Bonaventura, J., Lesniak, W., Mathews, W.B., Sysa-Shah, P., Rodriguez, L.A., Ellis, R.J., Richie, C.T., Harvey, B.K., Dannals, R.F., et al. (2017). Chemogenetics revealed: DREADD occupancy and activation via converted clozapine. Science (New York, NY) 357, 503-507.

Harris RJ (1994) ANOVA: An analysis of variance primer: Peacock.

Hamlin, A.S., Newby, J., and McNally, G.P. (2007). The neural correlates and role of D1 dopamine receptors in renewal of extinguished alcohol-seeking. Neuroscience 146, 525-536.

Heymann, G., Jo, Y.S., Reichard, K.L., McFarland, N., Chavkin, C., Palmiter, R.D., Soden, M.E., and Zweifel, L.S. (2019). Synergy of distinct dopamine projection populations in behavioral reinforcement. Neuron, in press. 
Ikemoto, S. (2007). Dopamine reward circuitry: two projection systems from the ventral midbrain to the nucleus accumbens-olfactory tubercle complex. Brain Research Reviews 56, 27-78.

Ikemoto, S., Qin, M., and Liu, Z.H. (2005). The functional divide for primary reinforcement of $\mathrm{D}$-amphetamine lies between the medial and lateral ventral striatum: is the division of the accumbens core, shell, and olfactory tubercle valid? The Journal of Neuroscience 25, 5061-5065.

Janak, P.H., Chang, J.Y., and Woodward, D.J. (1999). Neuronal spike activity in the nucleus accumbens of behaving rats during ethanol self-administration. Brain Research 817, 172-184.

Jean-Richard-dit-Bressel, P., Clifford, C.W.G., and McNally, G.P. (2020). Analyzing event-related transients: Confidence intervals, permutation tests, and consecutive thresholds. Frontiers in Molecular Neuroscience 13.

Jonas, D.E., Amick, H.R., Feltner, C., Bobashev, G., Thomas, K., Wines, R., Kim, M.M., Shanahan, E., Gass, C.E., Rowe, C.J., et al. (2014). Pharmacotherapy for adults with alcohol use disorders in outpatient settings: a systematic review and meta-analysis. JAMA 311, 1889-1900.

Kriegeskorte, N., and Kievit, R.A. (2013). Representational geometry: integrating cognition, computation, and the brain. Trends Cogn Sci 17, 401-412.

Kriegeskorte, N., Mur, M., and Bandettini, P. (2008a). Representational similarity analysis - connecting the branches of systems neuroscience. Frontiers in System Neuroscience 2, 4.

Kriegeskorte, N., Mur, M., Ruff, D.A., Kiani, R., Bodurka, J., Esteky, H., Tanaka, K., and Bandettini, P.A. (2008b). Matching categorical object representations in inferior temporal cortex of man and monkey. Neuron 60 , 1126-1141.

Lammel, S., Hetzel, A., Hackel, O., Jones, I., Liss, B., and Roeper, J. (2008). Unique properties of mesoprefrontal neurons within a dual mesocorticolimbic dopamine system. Neuron 57, 760-773.

Lammel, S., Ion, D.I., Roeper, J., and Malenka, R.C. (2011). Projection-specific modulation of dopamine neuron synapses by aversive and rewarding stimuli. Neuron 70, 855-862.

Lammel, S., Lim, B.K., Ran, C., Huang, K.W., Betley, M.J., Tye, K.M., Deisseroth, K., and Malenka, R.C. (2013). Input-specific control of reward and aversion in the ventral tegmental area. Nature 491, 212-217.

Liu, Z., Brown, A., Fisher, D., Wu, Y., Warren, J., and Cui, X. (2016). Tissue specific expression of cre in rat tyrosine hydroxylase and dopamine active transporter-positive neurons. PLoS One 11, e0149379.

Luscher, C. (2015). The emergence of a circuit model for addiction. Annual Review of Neuroscience 39, annurev-neuro-070815-013920-070820.

Mahler, S.V., Vazey, E.M., Beckley, J.T., Keistler, C.R., McGlinchey, E.M., Kaufling, J., Wilson, S.P., Deisseroth, K., Woodward, J.J., and Aston-Jones, G. (2014). Designer receptors show role for ventral pallidum input to ventral tegmental area in cocaine seeking. Nature Neuroscience 17, 577-585.

Marchant, N.J., Whitaker, L.R., Bossert, J.M., Harvey, B.K., Hope, B.T., Kaganovsky, K., Adhikary, S., Prisinzano, T.E., Vardy, E., Roth, B.L., et al. (2016). Behavioral and physiological effects of a novel kappa opioid receptor based DREADD in rats. Neuropsychopharmacology 41, 402-409.

Marlatt, G.A. (1996). Taxonomy of high-risk situations for alcohol relapse: Evolution and development of a cognitive-behavioral model. Addiction 91, S37-S49.

Marlatt, G.A., and Donovan, D.M. (2005). Relapse prevention (New York: Guildford Press).

McFarland, K., and Kalivas, P.W. (2001). The circuitry mediating cocaineinduced reinstatement of drug-seeking behavior. The Journal of Neuroscience 21, 8655-8663.

Meredith, G.E., Pennartz, C.M.a., and Groenewegen, H.J. (1993). The cellular framework for chemical signalling in the nucleus accumbens Progress in Neurobiology 99, 3-24.

Mohebi, A., Pettibone, J.R., Hamid, A.A., Wong, J.-M.T., Vinson, L.T., Patriarchi, T., Tian, L., Kennedy, R.T., and Berke, J.D. (2019). Dissociable dopamine dynamics for learning and motivation. Nature, 570, 65-70.
Nili, H., Wingfield, C., Walther, A., Su, L., Marslen-Wilson, W., and Kriegeskorte, N. (2014). A toolbox for representational similarity analysis. PLoS Computational Biology 10, e1003553.

Nutt, D.J., Lingford-Hughes, A., Erritzoe, D., and Stokes, P.R.A. (2015). The dopamine theory of addiction: 40 years of highs and lows. Nature Reviews Neuroscience 16, 305-312.

Patriarchi, T., Cho, J.R., Merten, K., Howe, M.W., Marley, A., Xiong, et al. (2018). Ultrafast neuronal imaging of dopamine dynamics with designed genetically encoded sensors. Science 360, eaat 4422 .

Phillips, P.E.M., Stuber, G.D., Heien, M.L.A.V., Wightman, R.M., and Carelli, R.M. (2003). Subsecond dopamine release promotes cocaine seeking. Nature 422, 614-617.

Prasad, A.A., Xie, C., Chaichim, C., Nguyen, J.H., McClusky, H.E., Killcross, S., Power, J.M., and McNally, G.P. (2020). Complementary roles for ventral pallidum cell types and their projections in relapse. The Journal of Neuroscience 40, 880-893.

Saunders, B.T., Richard, J.M., Margolis, E.B., and Janak, P.H. (2018). Dopamine neurons create Pavlovian conditioned stimuli with circuit-defined motivational properties. Nature Neuroscience 21, 1072-1083.

Schmidt, H.D., Anderson, S.M., Famous, K.R., Kumaresan, V., and Pierce, R.C. (2005). Anatomy and pharmacology of cocaine priming-induced reinstatement of drug seeking. European Journal of Pharmacology 526, 6576.

Stout, R.L., Longabaugh, R., and Rubin, A. (1996). Predictive validity of Marlatt's relapse taxonomy versus a more general relapse code. Addiction 91, S99S110.

Stuber, G.D., Roitman, M.F., Phillips, P.E., Carelli, R.M., and Wightman, R.M. (2005a). Rapid dopamine signaling in the nucleus accumbens during contingent and noncontingent cocaine administration. Neuropsychopharmacology 30, 853-863.

Stuber, G.D., Wightman, R.M., and Carelli, R.M. (2005b). Extinction of cocaine self-administration reveals functionally and temporally distinct dopaminergic signals in the nucleus accumbens. Neuron 46, 661-669.

Tian, J., Huang, R., Cohen, J.Y., Osakada, F., Kobak, D., Machens, C.K., Callaway, E.M., Uchida, N., and Watabe-Uchida, M. (2016). Distributed and mixed information in monosynaptic inputs to dopamine neurons. Neuron 91 , 1374-1389.

Todd, T.P., Vurbic, D., and Bouton, M.E. (2014). Behavioral and neurobiological mechanisms of extinction in Pavlovian and instrumental learning. Neurobiology of Learning and Memory 108, 52-64.

Vardy, E., Robinson, J.E., Li, C., Olsen, R.H.J., DiBerto, J.F., Giguere, P.M., Sassano, F.M., Huang, X.-P., Zhu, H., Urban, D.J., et al. (2015). A New DREADD Facilitates the Multiplexed Chemogenetic Interrogation of Behavior. Neuron, 86, 936-946.

Volkow, N.D., Wise, R.A., and Baler, R. (2017). The dopamine motive system: implications for drug and food addiction. Nature Reviews Neuroscience 18, 741-752.

Watabe-Uchida, M., Zhu, L., Ogawa, S.K., Vamanrao, A., and Uchida, N. (2012). Whole-brain mapping of direct inputs to midbrain dopamine neurons. Neuron 74, 1-12.

Willcocks, A.L., and McNally, G.P. (2011). The role of context in re-acquisition of extinguished alcoholic beer-seeking. Behavioral Neuroscience 125, 541550 .

Willcocks, A.L., and McNally, G.P. (2014). An extinction retrieval cue attenuates renewal but not reacquisition of alcohol seeking. Behavioral Neuroscience 128, 83-91.

Woodward, D.J., Chang, J.Y., Janak, P., Azarov, A., and Anstrom, K. (2000). Activity patterns in mesolimbic regions in rats during operant tasks for reward. Progress in Brain Research 126, 303-322.

Yang, H., de Jong, J.W., Tak, Y., Peck, J., Bateup, H.S., and Lammel, S. (2018). Nucleus accumbens subnuclei regulate motivated behavior via direct inhibition and disinhibition of VTA dopamine subpopulations. Neuron 97, 434-449. 
bioRxiv preprint doi: https://doi.org/10.1101/2020.03.06.981605; this version posted March 8, 2020. The copyright holder for this preprint (which was not certified by peer review) is the author/funder. All rights reserved. No reuse allowed without permission.

Figure S1. VTA TH neurons mediate relapse (A) Location of hM4Di expression in

midbrain with each rat represented at $25 \%$ opacity. (B) Location of KORD expression in

midbrain with each rat represented at $25 \%$ opacity. (C) Example of hM4Di expression in

VTA TH neurons. (D) No effects of hM4Di VTA TH neuron inhibition on latency to first active nosepoke during renewal or reacquisition or on locomotor activity. 
bioRxiv preprint doi: https://doi.org/10.1101/2020.03.06.981605; this version posted March 8, 2020. The copyright holder for this preprint (which was not certified by peer review) is the author/funder. All rights reserved. No reuse allowed without permission.

A $\quad-5.04 \mathrm{~mm}$

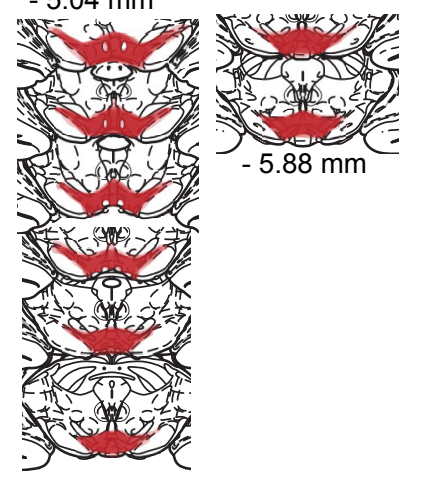

B

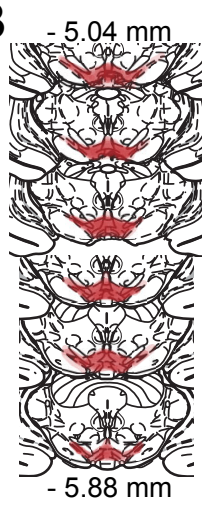

C

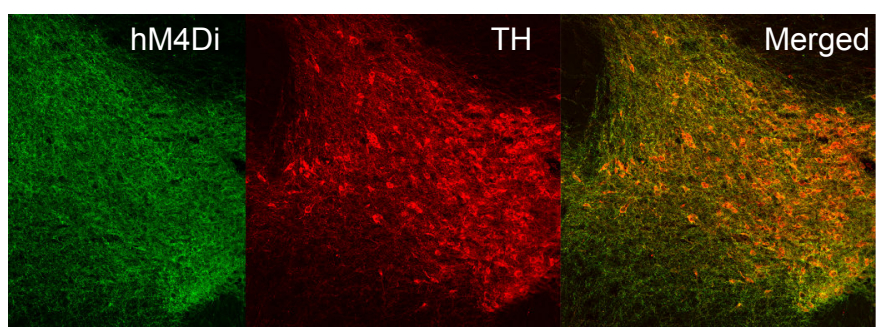

D

Latency to First Active Nosepoke

Locomotion

Locomotion
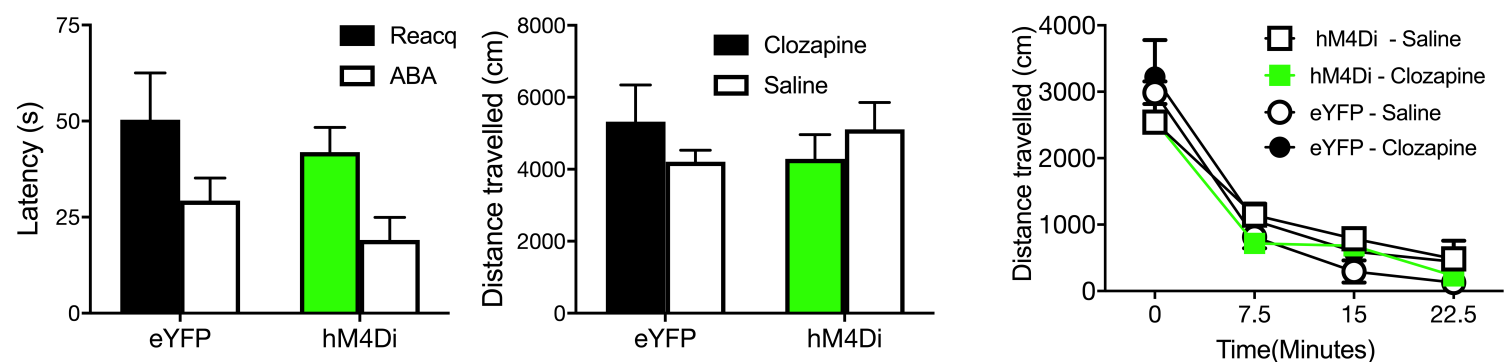
bioRxiv preprint doi: https://doi.org/10.1101/2020.03.06.981605; this version posted March 8, 2020. The copyright holder for this preprint (which was not certified by peer review) is the author/funder. All rights reserved. No reuse allowed without permission.

Figure S2. VTA fibre photometry (A) Location of gCaMP6 expression and fibre tips in

midbrain with each rat represented at $25 \%$ opacity. The lateral edge of the fascicuus retroflexus was used as anatomical boundary between mVTA and IVTA. Example of gCaMP6 expression in VTA TH neurons. (B) Mean \pm SEM calcium transients in VTA TH neurons from $-3 \mathrm{~s}$ to $3 \mathrm{~s}$ around Magazine+ (first magazine entry after Nosepoke+) and Magazine- (magazine entries at other times) for mVTA and IVTA. Coloured bars above traces show periods (with minimum consecutive threshold) of significant difference from 0 as defined by $95 \%$ confidence intervals. (C) Comparison of actual $\mathrm{df} / \mathrm{f}$ and normalized waveform kernels. Normalized kernels were obtained by normalising each trial waveform according to its sum square deviation from 0 and were used for further analysis. 
A

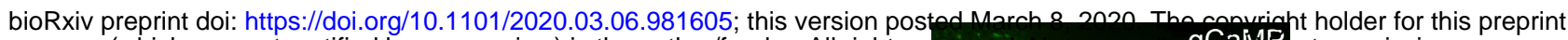
(which was nof gertified by peer review) is the author/funder. All rights $r$

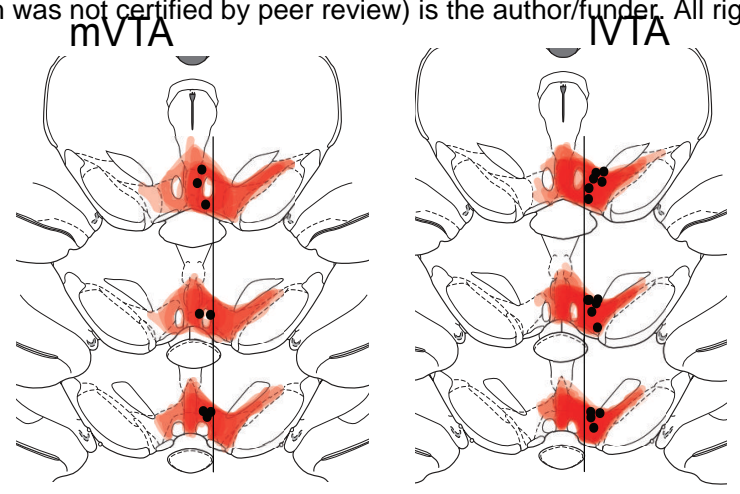
gCalif put permission.

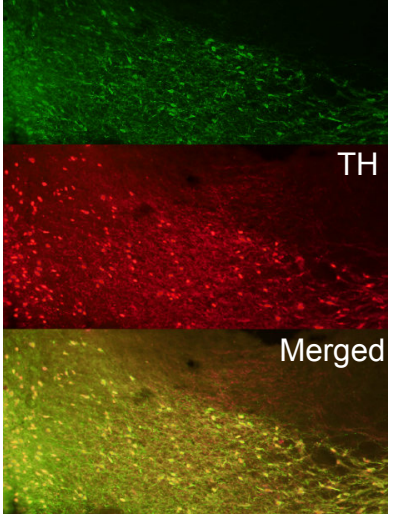

\section{B Early} Acquisition
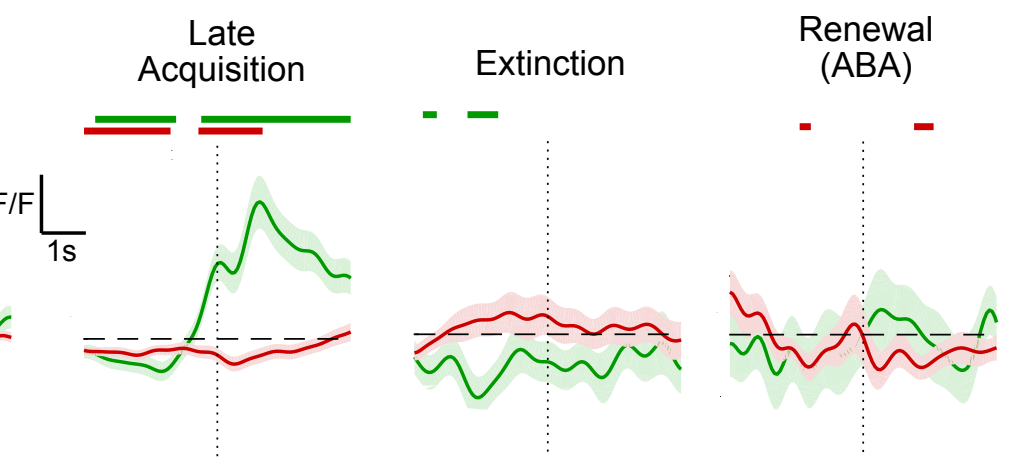

Reacquisition
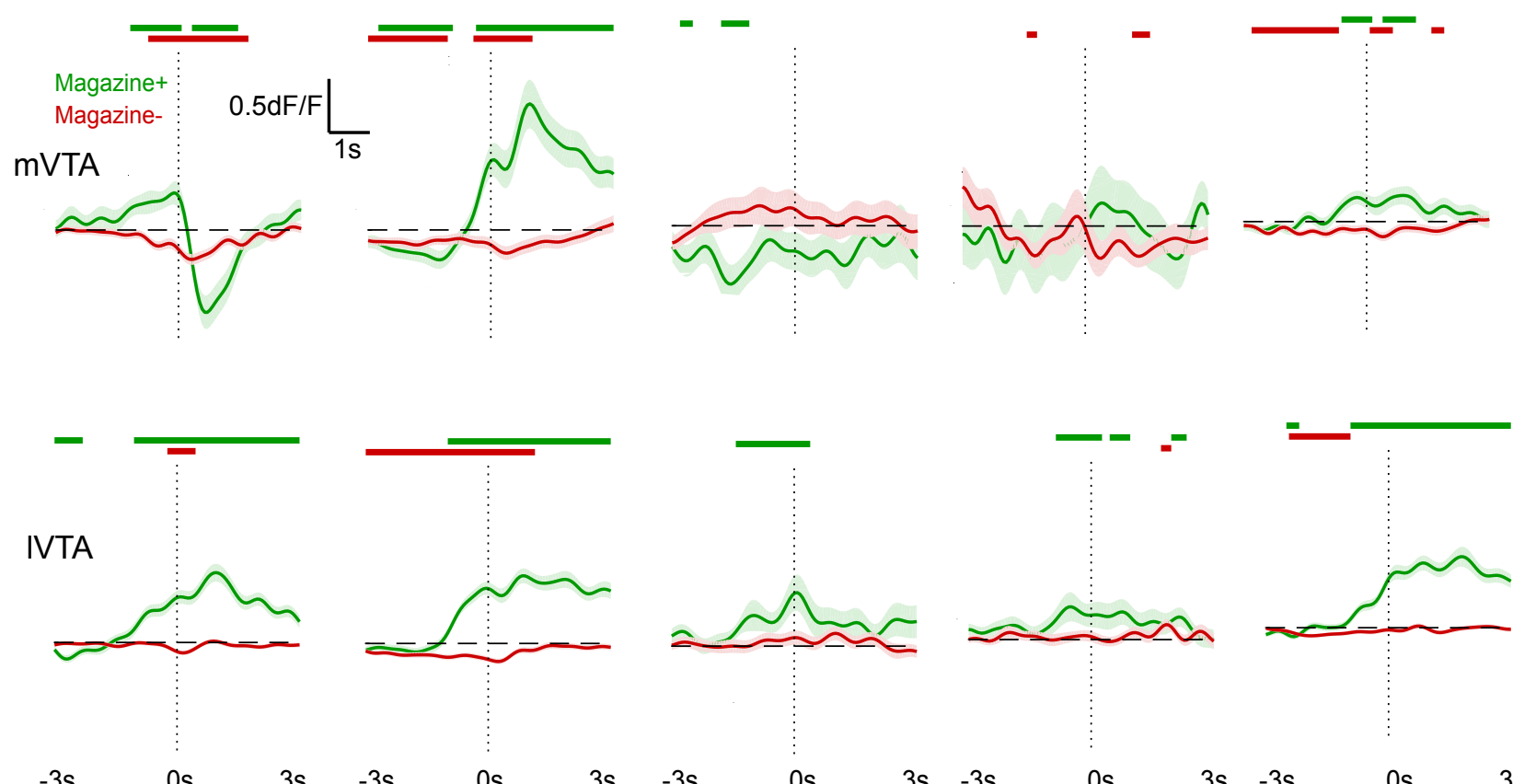

$-3 s$

Os $\quad 3 s$ 3s $-3 s$

\section{C}
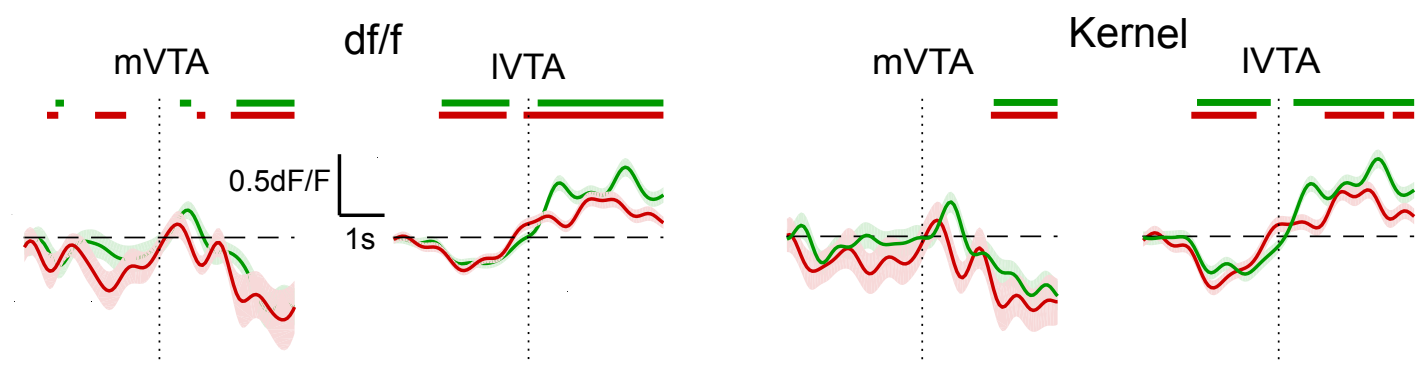
bioRxiv preprint doi: https://doi.org/10.1101/2020.03.06.981605; this version posted March 8, 2020. The copyright holder for this preprint (which was not certified by peer review) is the author/funder. All rights reserved. No reuse allowed without permission.

Figure S3. VTA optogenetic inhibition and relapse (A) Location of eNpHR3.0 expression and fibre tips in midbrain with each rat represented at $25 \%$ opacity. The lateral edge of the fasciculus retroflexus was used as anatomical boundary between mVTA and IVTA. Example of eNpHR3.0 expression in VTA TH neurons. (B) Mean \pm SEM nosepokes during test in extinction and training contexts. Rats refrained from alcohol-seeking in the extinction context but relapsed to alcohol-seeking in the training context (context main effect: $F(1,17)=33.83$, $p<0.001$; nosepoke main effect $F(1,17)=32.68, p<0.001$; context $x$ nosepoke interaction, $F(1,17)=43.30, p<0.001)$ (Figure 1B), showing renewal (context-induced reinstatement) of alcohol-seeking. IVTA optogenetic inhibition around Nosepoke+ reduced responding on $A B A$ test (main effect group $F(1,17)=8.93, p=0.008$; group $x$ context interaction $F(1,17)=5.11, p=0.037$ ) whereas mVTA inhibition did not (main effect group $F$ $(1,17)=0.17, p=0.69$; group $x$ context interaction $F(1,17)=0.09, p=0.77)$. Mean \pm SEM nosepokes during reacquisition test. IVTA (main effect group $F(1,17)=25.18, p<0.001$; group $x$ nosepoke interaction $F(1,17)=26.22, p<0.001$ ) and mVTA (main effect group $F$ $(1,17)=12.47, p=0.003$; group $x$ nosepoke interaction $F(1,17)=14.04, p=0.002)$ inhibition around Nosepoke+ reduced reacquisition. ${ }^{*} p<.05$. 
bioRxiv preprint doi: https://doi.org/10.1101/2020.0340928tha5; this version posted March 8, 2020. The copyright holder for this preprint A (which was not certified by peer revjew) is the author/funder. All riahtc rocorved No reuse allowed without permission.

AAV5 DIO::eNpHR3.0
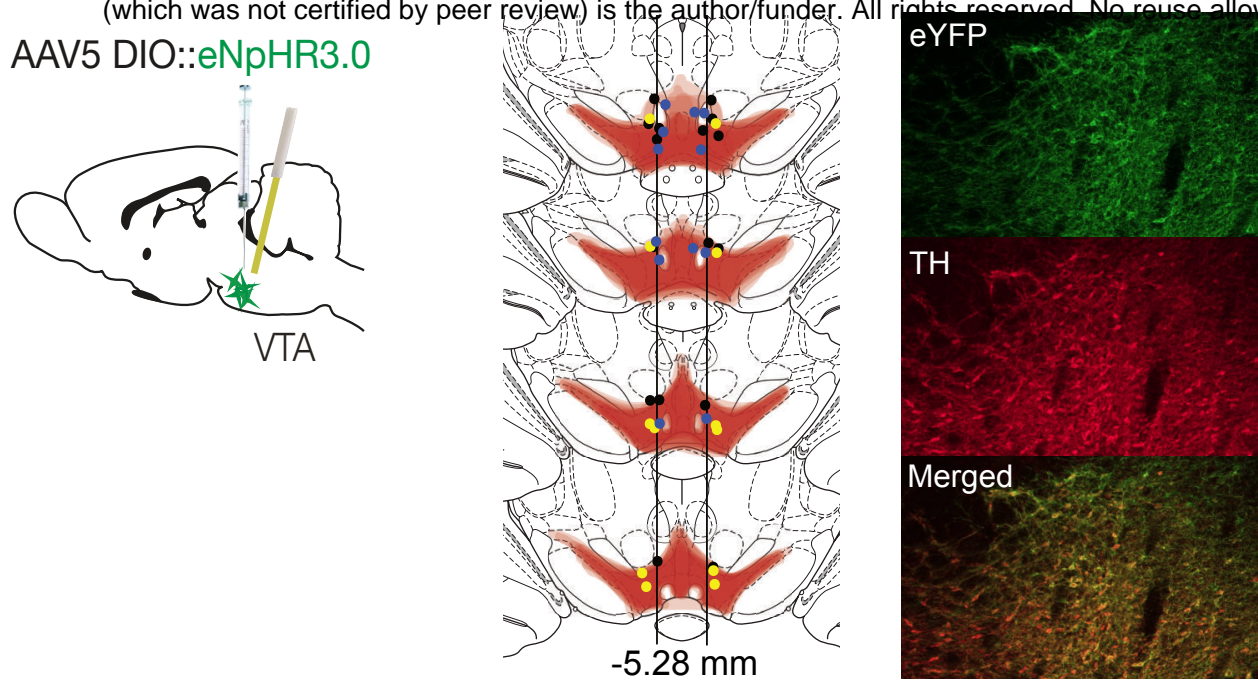

B

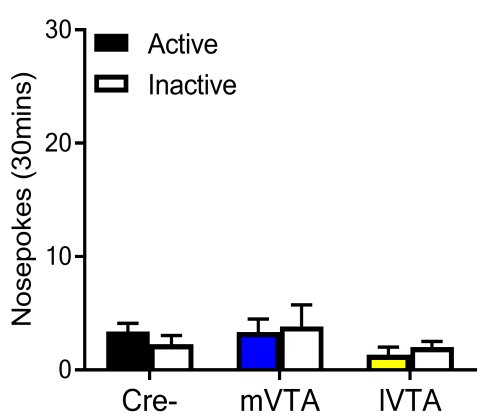

Reacquisition

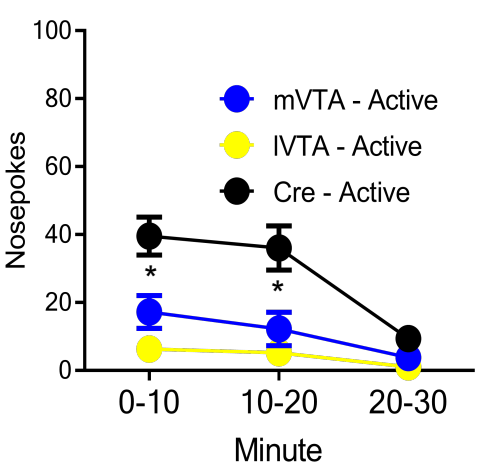

ABA

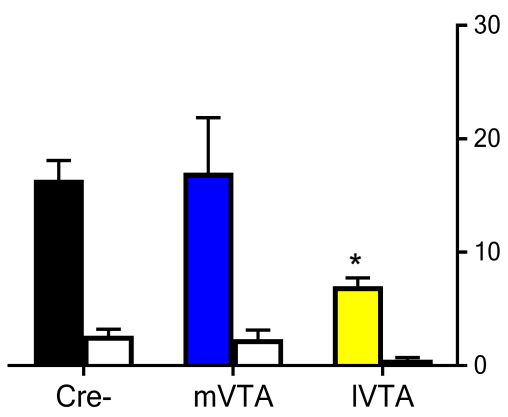

Reacquisition

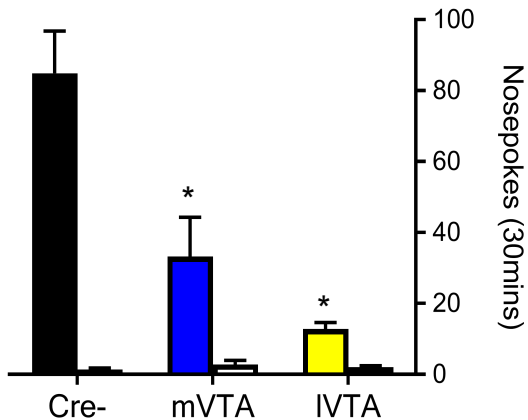


bioRxiv preprint doi: https://doi.org/10.1101/2020.03.06.981605; this version posted March 8, 2020. The copyright holder for this preprint (which was not certified by peer review) is the author/funder. All rights reserved. No reuse allowed without permission.

Figure S4. Dopamine and relapse. (A). Effects of SCH39166 on renewal. Mean \pm SEM

nosepokes during test in extinction and training contexts. Rats refrained from alcoholseeking in the extinction context but relapsed to alcohol-seeking in the training context (context main effect: $F(1,28)=21.85, p<0.001$; nosepoke main effect $F(1,28)=51.55, p$ $<0.001$; context $x$ nosepoke interaction, $F(1,28)=27.56, p<0.001)$. SCH39166 reduced renewal (context $x$ group interaction: $F(1,28)=29.13$ and context $x$ nosepoke $x$ group $F(1$, $28)=44.86, p<0.001)$, including at the lowest dose $(0.025 \mathrm{~m} / \mathrm{kg})($ context $x$ group interaction: $F(1,28)=21.69, p<0.001$ and context $x$ nosepoke $x$ group $F(1,28)=35.49, p$ $<0.001)$. (B). Effects of SCH39166 on reacquisition. Mean \pm SEM nosepokes during test for reacquisition. $\mathrm{SCH} 39166$ reduced reacquisition (group main effect: $F(1,28)=57.40$ and group $x$ nosepoke interaction $F(1,28)=59.66, p<0.001)$, including at the lowest dose $(0.025 \mathrm{~m} / \mathrm{kg})(0 \vee 0.025 \mathrm{mg} / \mathrm{kg}$ main effect: $F(1,28)=35.87, \mathrm{p}<0.001$ and group $x$ nosepoke $F(1,28)=36.46, p<0.001)$. (C). Effect of SCH39166 on latency to first active nosepoke and locomotor activity. There was an overall effect of SCH39166 on latency to first active nosepoke (main effect of drug $F(1,28)=4.55, p=0.04$ ) and a linear effect of SCH39166 dose $(F(1,28)=11.72, p=0.0019)$. Importantly, there was no effect of the lowest dose of $\mathrm{SCH} 39166(\mathrm{~F}(1,28)=0.006, \mathrm{p}=0.939)$ even though this dose reduced relapse. There were no interactions with test session (ABA, Reacquisition). There was no overall effect of SCH39166 on locomotor activity (main effect $F(1,28)=0.84, p=0.37$ ). Locomotor activity was reduced at the highest dose $(0.25 \mathrm{mg} / \mathrm{kg}$ ) (linear trend across dose: $F(1,28)=23.91, p<0.001)$. Critically, the lowest dose $(0.025 \mathrm{mg} / \mathrm{kg})$ which reduced relapse did not affect locomotor activity compared to $0 \mathrm{mg} / \mathrm{kg}(F(1,28)=2.43, \mathrm{p}=0.13)$. (D). dLight Histology. Location of dLight1.1 expression and fibre tips in nucleus accumbens with each rat represented at $25 \%$ opacity (E). dLight transients. Mean \pm SEM dopamine transients from $-3 \mathrm{~s}$ to $3 \mathrm{~s}$ around Magazine+ for AcbShM, AcbC, AcbShL. Green bars above traces show periods (with minimum consecutive threshold) of significant difference from 0 as defined by $95 \%$ confidence intervals. 
A

Extinction (ABB)

Renewal (ABA)

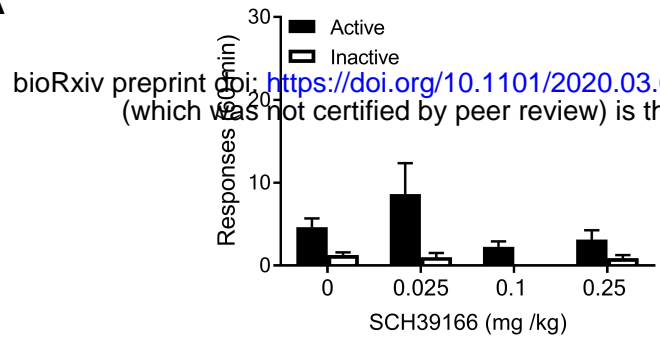

B
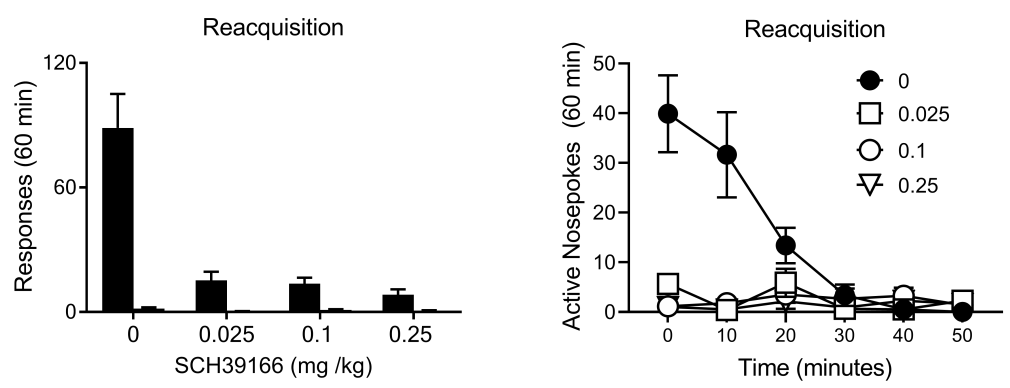

C

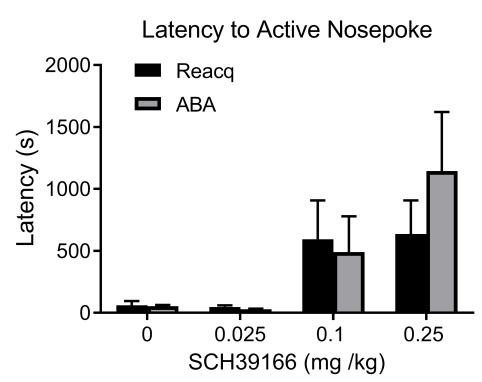

D

E
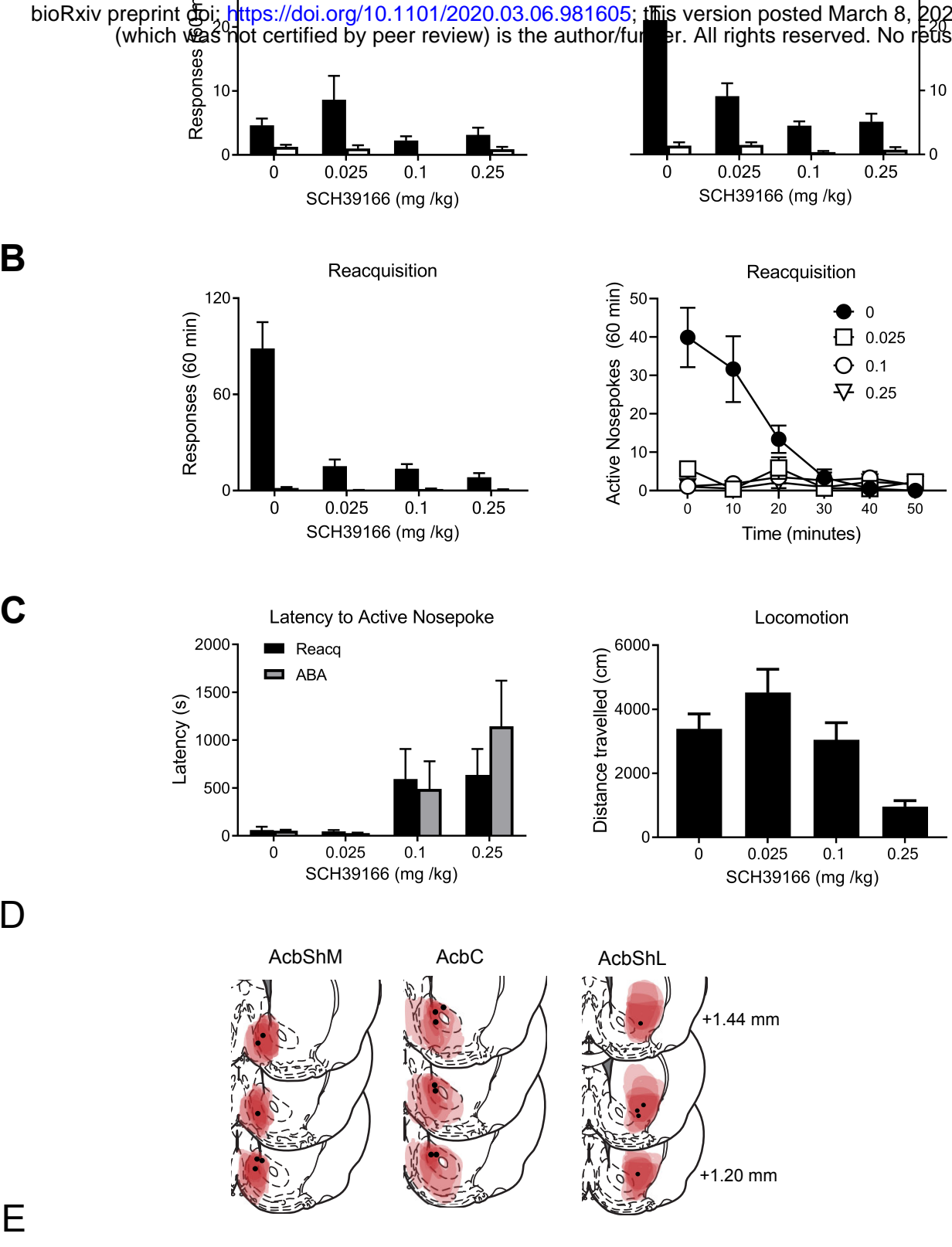

AcbShM

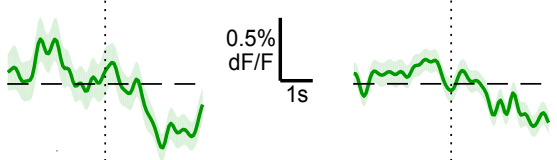

AcbC<smiles>CNC1CCCC1C</smiles>

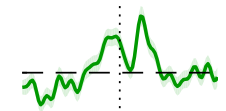

AcbShL

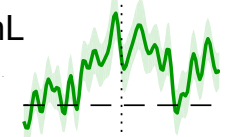<smiles>[Li]C1CCCC1</smiles>

$-3 s$

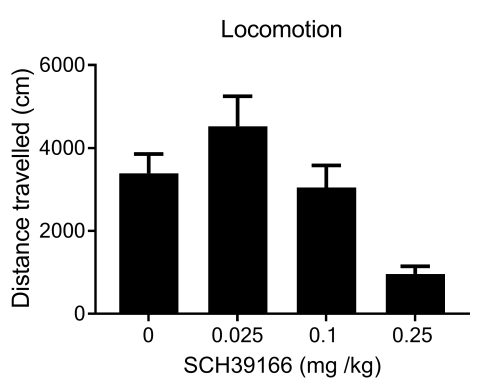

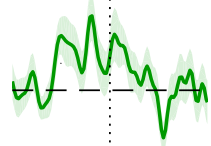

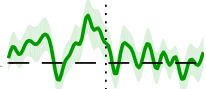

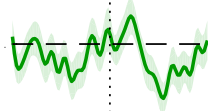

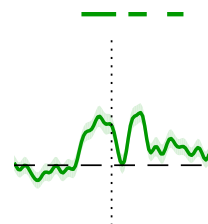

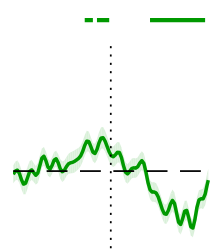
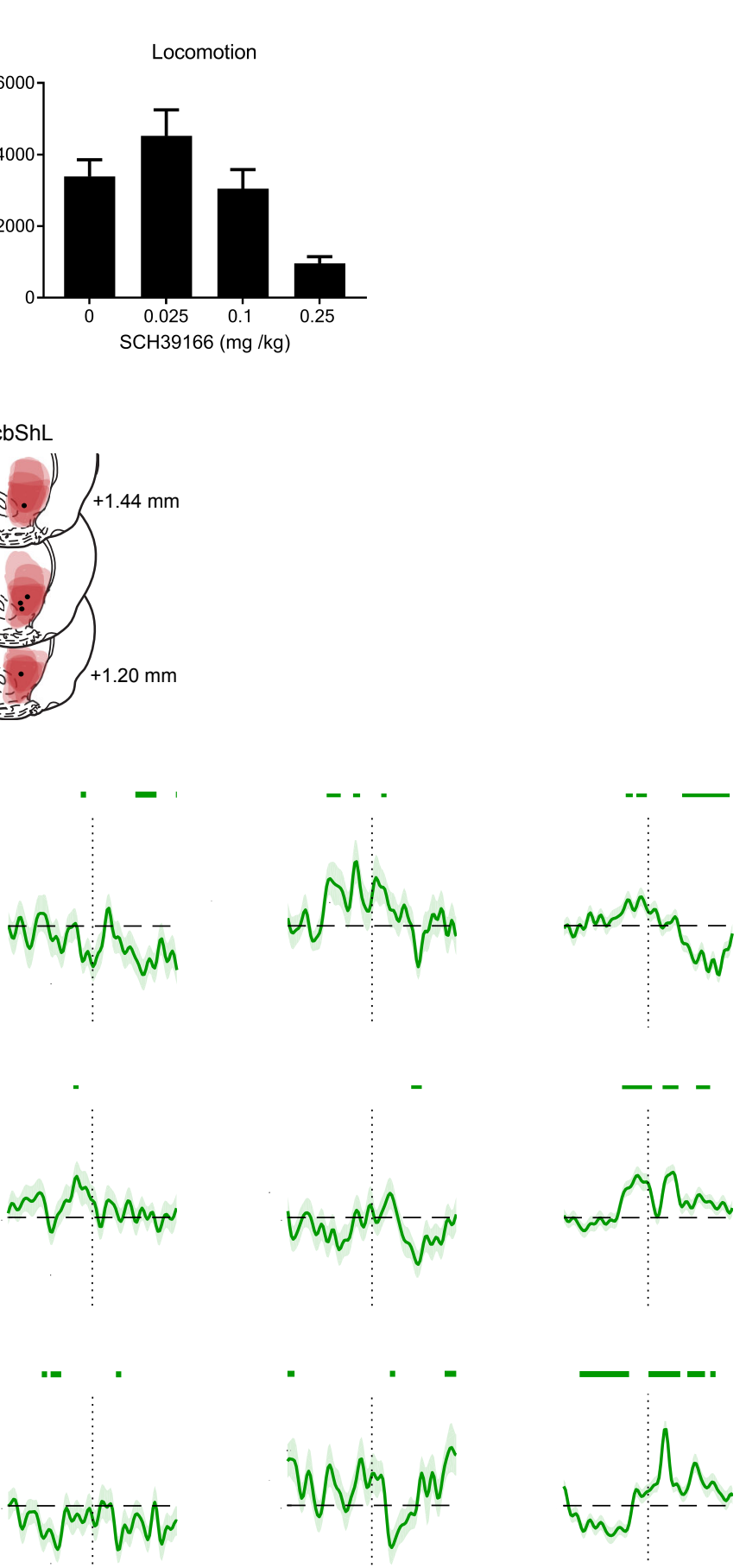